\title{
Resource Selection by an Endangered Ungulate: A Test of Predator-Induced Range Abandonment
}

\author{
Jeffrey T. Villepique, ${ }^{1,2,3}$ Becky M. Pierce, ${ }^{1,2}$ Vernon C. Bleich, \\ Aleksandra Andic, ${ }^{4}$ and R. Terry Bowyer ${ }^{1}$ \\ ${ }^{1}$ Department of Biological Sciences, Idaho State University, 921 South 8th Avenue, Stop 8007, Pocatello, ID 83209, USA \\ ${ }^{2}$ Sierra Nevada Bighorn Sheep Recovery Program, California Department of Fish and Wildlife, 407 West Line Street, \\ Bishop, CA 93514, USA \\ ${ }^{3}$ California Department of Fish and Wildlife, P.O. Box 3222, Big Bear City, CA 92314, USA \\ ${ }^{4}$ Department of Astronomy, New Mexico State University, P.O. Box 30001, MSC 4500, Las Cruces, NM 88003-8000, USA
}

Correspondence should be addressed to Jeffrey T. Villepique; jvillepique@gmail.com

Received 30 September 2014; Accepted 3 January 2015

Academic Editor: Tomasz S. Osiejuk

Copyright (C) 2015 Jeffrey T. Villepique et al. This is an open access article distributed under the Creative Commons Attribution License, which permits unrestricted use, distribution, and reproduction in any medium, provided the original work is properly cited.

\begin{abstract}
We investigated influences of risk of predation by mountain lions (Puma concolor), topographic metrics at multiple scales, and vegetation, land, and snow cover on resource selection by Sierra Nevada bighorn sheep (Ovis canadensis sierrae), an endangered taxon, during winters 2002-2007, in the Sierra Nevada, California, USA. We hypothesized that those mountain ungulates would trade off rewards accrued from using critical low-elevation habitat in winter for the safety of areas with reduced risk of predation. Sierra Nevada bighorn sheep did not trade off benefits of forage for reduced risk of predation but selected areas of high solar radiation, a correlate of vegetation productivity, where risk of predation by mountain lions was greatest, while mitigating indirect risk of predation by selecting for steep, rugged terrain. Bighorn sheep selected more strongly for areas where mountain lions were active, than for low-elevation habitat in winter, likely because mountain lions were most active in those areas of bighorn sheep winter ranges overlapping ranges of mule deer (Odocoileus hemionus), where both ungulates accrued forage benefits. We demonstrated reduced benefit of migration to low elevation during drought years, providing an alternative explanation to the predator-induced abandonment hypothesis for the disuse of low-elevation winter range observed during drought years.
\end{abstract}

\section{Introduction}

Animals living in temperate or arctic environments, where a seasonal abundance of forage coincides with increased nutrient demands of late gestation and lactation [1-3], must balance the need to acquire nutrients against constraints from risk of predation [4-6]. Many populations of ungulates migrate between discrete seasonal ranges [7-13], with those occupying montane environments obtaining high-quality resources by selecting among elevations that enable exploitation of new growth in forage [11, 14]. Benefits of migration to areas of high-quality forage must outweigh increased risk of predation to comprise an evolutionarily stable strategy [15]. Populations of mountain sheep (Ovis spp.) occupying montane environments may migrate between high-elevation summer ranges and lower-elevation winter ranges, corresponding to the progression of new growth in grasses, forbs, and shrubs [16-18]. Variation in temperature, precipitation, and vegetation phenology, however, may alter behavior and habitat selection by mountain sheep $[13,19,20]$.

Predator avoidance operates through indirect mechanisms that affect the likelihood of encountering, detecting, or eluding a predator, as well as through direct means by which animals minimize the odds of success of a predator in capturing prey upon detection [21,22]. Direct mechanisms of predator avoidance include sight $[23,24]$, as well as olfactory and auditory cues to proximate risk posed by a predator [25-27]. Mountain sheep also may assess the likelihood of 
encountering and escaping a predator indirectly, as a function of habitat, in the absence of overt signs of a predator $[13,28$, 29]. Visually unobstructed habitats enable ocular detection of predators $[13,24,30]$, whereas proximity to a refuge (e.g., steep and rugged escape terrain $[17,31]$ ) may confer protection from some predators, in part, because coursing predators seldom use those areas (e.g., coyotes, Canis latrans [32]; gray wolves, C. lupus [4, 33]). Differences between the sexes in risk tolerance and predator avoidance strategies [29, $32,34,35]$ must be accounted for in models of resource selection under risk of predation.

Selection of resources is subject to constraints imposed by perceived risk; sublethal effects of risk of predation may have profound influences on behavior and habitat selection [36, 37] and incur physiological costs [38]. There was, however, no association between sublethal response to risk of predation by wolves on pregnancy or body condition in North American elk (Cervus elaphus [39]). Responses to fear of predation have been posited to drive shifts in habitat selection, ultimately resulting in negative demographic effects among large herbivores [40, 41].

Mountain lions (Puma concolor) are the primary predators of mountain sheep in areas of sympatry and have been implicated as a threat to populations of Sierra Nevada bighorn sheep (O. canadensis sierrae [41]), an endangered taxon [42]. These large felids may cause substantial mortality in some populations of mountain sheep [43-46], but questions remain about the potential for sublethal effects as a consequence of changes in behavior or habitat selection by bighorn sheep. A precipitous decline in the largest population of Sierra Nevada bighorn sheep at Mount Baxter, California, USA, from 1987 to 1991, was attributed to decreased recruitment after females failed to occupy high-quality, low-elevation winter ranges in response to risk of predation by mountain lions [41]. Wehausen [41] concluded that "range abandonment" by Sierra Nevada bighorn sheep was a response to perceived risk of predation. Alternative explanations, such as the effect of 6 years of drought $[47,48]$ on forage or the potential demographic consequences of removal of large numbers of bighorn sheep from the winter range for translocation [49], however, have not been adequately investigated [50]. While evaluation of the predator-induced range abandonment hypothesis [41] is limited by the absence of information from telemetered animals, and by a lack of information on habitat conditions, an evaluation of indices of snow cover and forage conditions from the period of reported range abandonment is possible using archived, remotely sensed data. Those habitat factors likely played a principal role in winter habitat selection by bighorn sheep.

Snow cover may be reliably indexed through remote sensing of normalized difference snow index (NDSI) [51, 52] and variation in forage quality and quantity indexed by normalized difference vegetation index (NDVI), calculated from multispectral satellite imagery, at spatial and temporal resolutions dictated by the satellite platform employed [53]. Peak values of NDVI also were correlated with values of fecal crude protein [54], an index of dietary quality [55], thereby validating NDVI as a useful index to quality of forage used by ungulates.
For sublethal effects of predation risk to result in the severe demographic consequences posited by Wehausen [41], bighorn sheep must have made disproportionate tradeoffs by giving up nutrients in exchange for reduced risk of predation. Under that predator-induced abandonment hypothesis, a landscape-scale shift in habitat selection must have occurred, wherein Sierra Nevada bighorn sheep avoided traditional low-elevation winter ranges in response to risk of predation from mountain lions, trading off benefits of forage at low elevation for reduced risk by use of high-elevation habitat. We tested the overarching hypothesis that bighorn sheep subject to substantial risk of predation would select areas of lesser risk, but with lower-quality forage, and concomitantly reduced nutrient availability, in both wet and dry years (Table 1). Alternatively, if landscape-scale movements are not evident, we expected bighorn sheep to remain in areas with high predation risk to access quality forage, while exhibiting antipredator behaviors through fine-scale selection of rugged and steep terrain (Table 1).

\section{Methods}

The study area was the eastern slope of the Sierra Nevada, a rugged escarpment rising from the Owens Valley and forming the western boundary of the Great Basin in eastern California, USA. The highest peaks and steepest slopes are located in the southern portion of the range in Inyo and Mono counties, California (centroid $37^{\circ} 11^{\prime} \mathrm{N}, 118^{\circ} 23^{\prime} \mathrm{W}$ ), where four distinct populations of Sierra Nevada bighorn sheep occupied rugged granitic slopes (Mono Basin, Wheeler Ridge, Mount Baxter, and Mount Langley [29]; Figure 1). We focused on the two largest populations of Sierra Nevada bighorn sheep: Wheeler Ridge and Mount Baxter. Elevations of winter ranges were 1,500-4,100 $\mathrm{m}$ at Wheeler Ridge and $1,300-4,100 \mathrm{~m}$ at Mount Baxter. Winter ranges of both populations of bighorn sheep overlap winter ranges of migratory herds of mule deer (Odocoileus hemionus [56]). The predominant vegetation community at low elevation was Great Basin sagebrush steppe, dominated by sagebrush (Artemisia tridentata) and antelope bitterbrush (Purshia tridentata [57]), whereas mountain whitethorn (Ceanothus cordulatus), mountain mahogany (Cercocarpus ledifolius), and horsebrush (Tetradymia canescens) were common at middle elevations. Trees, including Jeffrey pine (Pinus jeffreyi), and juniper (Juniperus occidentalis) were sparsely distributed throughout middle elevations, with grasses (Achnatherum speciosum, Festuca spp.) and buckwheat (Eriogonum spp.) common as understory species. At high elevations (3,300$4,300 \mathrm{~m}$ ), characteristic alpine vegetation included alpine crested wheatgrass (Agropyron spp.), sedges (Carex spp.), and vetches (Astragalus spp. [29]).

2.1. Animal Capture. During 2002-2007, we captured bighorn sheep with a net gun fired from a helicopter [58]. Bighorn sheep were physically restrained and transported to a central processing area where samples were collected and a GPS (global positioning system) collar (described later) and a small secondary collar containing a VHF (very high 
TABLE 1: Hypotheses and corollary predictions regarding the influence of direct and indirect predation risk, forage availability, and tradeoff of forage at low versus high elevation on habitat selection. For each of three general hypotheses, the prediction of selection for a corollary predictor is denoted (+), and avoidance denoted (-), where relevant, for female and male Sierra Nevada bighorn sheep in the Sierra Nevada, California, USA, 2002-2007.

Hypothesis and corollaries Hypothesis supported

(I) Habitat selection influenced by risk of predation

(A) Direct predation risk; surfaces generated from probability density functions of Active mountain lions

Yes

$(-)$

$(-)$

Yes

$(+)$

$(+)$

$(+)$

$(+)$

$(-)$

(+)

(-)

Yes

(-)

(+)

$(+)$

Yes

$(+)$

$(-)$
No

(+)

(+)

No

(-)

$(-)$

(-)

(-)

$\mathrm{n} / \mathrm{a}$

(-)

(+)

No

(+)

(-)

$(-)$

No

$\mathrm{n} / \mathrm{a}$

$\mathrm{n} / \mathrm{a}$ frequency) transmitter were fitted to adult ( $>1$ year old) bighorn sheep. Bighorn sheep were returned to the capture location for release.

We captured mountain lions from 2002 to 2009 by pursuit with hounds, employing techniques described by Pierce et al. $[59,60]$ or by opportunistic darting. Adult mountain lions were immobilized with Telazol (4.4 mg/kg [59]), with an extra-long-range projector (Palmer Cap-Chur, Inc., Powder Springs, Georgia, USA). When proximity to water presented a potential risk of drowning, we used darts equipped with a VHF transmitter (Pneudart Inc., Williamsport, Pennsylvania, USA) [61] to facilitate rapid location of mountain lions after immobilization. Mountain lions were fitted with GPS collars (described later) and monitored at the capture site until they regained mobility. Capture methods for bighorn sheep and mountain lions followed guidelines of the American Society of Mammalogists [62], and were approved by the Institutional Animal Care and Use Committee (protocol \#0202) at the University of Alaska Fairbanks.

2.2. Spatial Analysis: Bighorn Sheep. Four models of GPS collars were deployed on bighorn sheep: Advanced Telemetry Systems GPS 2100 ( $n=6$; Isanti, Minnesota, USA), Lotek Wireless 4400s ( $n=2$; Newmarket, Ontario, Canada), and Televilt Simplex $(n=16)$ and Televilt Telus
( $n=4$; TVP Positioning AB, Lindesberg, Sweden). Collars used heterogeneous fix schedules of 3-720 GPS locations/day, because some collars were programmed by collaborators addressing different objectives. Data from GPS collars were censored for 2 days after capture to decrease the influence of atypical movements immediately following capture [63], and erroneous GPS locations eliminated by screening in ArcView 3.2 (Environmental Systems Research Institute, Redlands, California, USA; ESRI) with the BadFix extension [64]. We analyzed data for animals with $\geq 10$ days of location data in winter (January-April).

We used Home Range Tools for ArcGIS [65] and ArcGIS 9.2 software (ESRI, Redlands, California, USA) to define the study area as the winter ranges available to the Wheeler Ridge and Mt. Baxter populations from composite home ranges for each population of bighorn sheep in winter. For purposes of defining the study area, data from GPS collars were rarified to one randomly selected location per animal, per week, to minimize autocorrelation and reduce the influence of heterogeneous sample size among individual animals. The 95\% adaptive-kernel home range was calculated with a smoothing factor of $80 \% h_{\text {ref }}$ that prevented polygons within home ranges from fragmenting [66] (Figure 1).

Analysis of resource selection used only high-quality locations, after elimination of 2D locations and those locations where dilution of precision (DOP) was $\geq 10[67,68]$. 


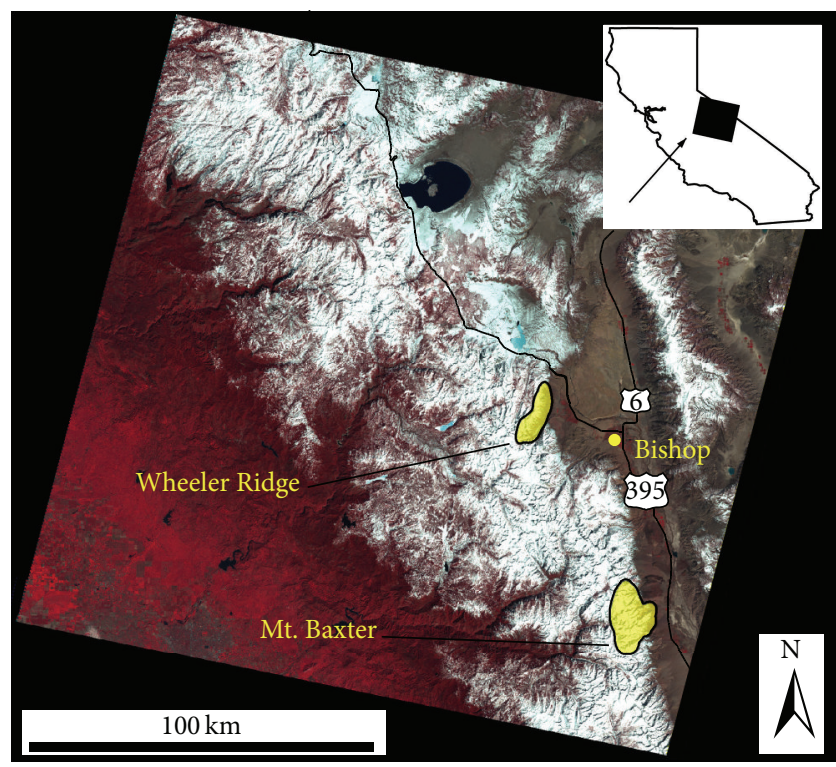

FIgURE 1: Landsat scene showing 95\% composite home ranges (yellow) for Wheeler Ridge and Mt. Baxter winter ranges of bighorn sheep. Mesic slopes to the west appear red in this false-color image (TM bands 4, 3, and 2) because photosynthetic activity is reflective of infrared radiation; snow-covered high elevations are visible in the center, with xeric areas visible on the east side, Sierra Nevada, California, USA (Path 42, Row 34, image date 11 March 2005).

Such screening introduced biases against detecting use of areas with high canopy closure or areas where available sky is obscured by topography [68-70]. Closed canopy was rare in our study area and, where present, generally was avoided by mountain sheep [17]. Cain III et al. [69] demonstrated a reduction in $3 \mathrm{D}$ fixes of $36 \%$ in areas with $<33 \%$ available sky versus those locations with $>66 \%$ available sky. We acknowledge a likely bias against detection of use in areas where proximity to steep escape terrain limited available sky necessary for satellite fixes. High-quality GPS data were rarified by selecting one location daily, nearest in time to solar noon, a timing chosen for consistency with historical data based on daytime visual observations [41]. We tested for independence of locations using the program ASSOC1 [71], assuming that animals with a proximity of $<200 \mathrm{~m}$ for $>25 \%$ of locations represented animals in the same group.

We calculated mean GPS location error, based on published error estimates [64, 67], and weighted by the proportion of GPS locations from each model of collar in our analysis, to assess appropriate scale for evaluation of thirdorder habitat selection $[72,73]$. Location error of 3D fixes, from previous studies, averaged $6.3 \mathrm{~m}$ (i.e., $50 \%$ circular error probable; $\mathrm{CEP}$ ) and $95 \% \mathrm{CEP}=28.6 \mathrm{~m}$. Ensuring that the accuracy of locations of animals is comparable to the scale of habitat maps is a key consideration when evaluating resource selection [73]. Our estimates of GPS location error were comparable to the accuracy of Landsat data used (approximately $\leq 30 \mathrm{~m}$, or 1 pixel; Section 2.6).

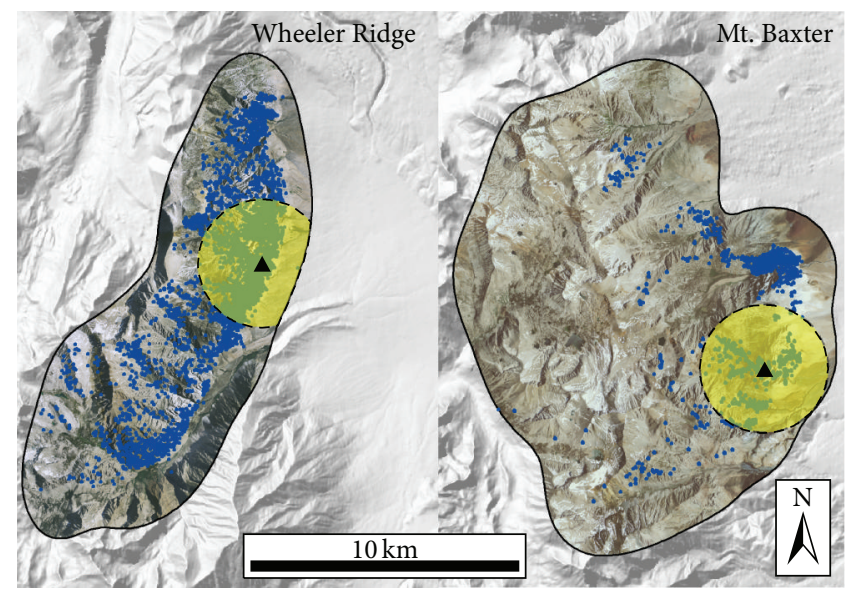

- Example GPS collar locations

¿-j Example $2.4 \mathrm{~km}$ availability radii

$\square$ Composite home ranges

- Daily GPS collar locations

FIgURE 2: Example of $2.4 \mathrm{~km}$ radius used to define available habitat for each GPS collar location in resource selection function (RSF) for Sierra Nevada bighorn sheep, California, USA, 2002-2007. Base map within composite home range from National Agricultural Imagery Program (NAIP) 2009 image (1-m scale, true color RGB).

2.3. Spatial Analysis: Random Locations. Resources available to bighorn sheep were quantified by casting ten random locations within a $2.4 \mathrm{~km}$ aerial radius of each midday bighorn sheep location (Figure 2) with Hawth's Analysis Tools 2.10 for ArcGIS 9.2 [74]. The $2.4 \mathrm{~km}$ radius reflected availability within a distance an animal could readily move in $24 \mathrm{~h}$ at the rate of $100 \mathrm{~m} / \mathrm{h}$ noted for $16.3 \%$ of movements during 1-36 h intervals between daily GPS locations, allowing evaluation of fine-scale selection, while also encompassing high and low elevations within the circle of availability [74, 75] (Figure 8). Random locations were further constrained by the $95 \%$ composite home range for bighorn sheep; random points falling outside that composite home range for the population were eliminated and new random points cast to achieve 10 random locations per animal location. Animal locations represented used points in the matched-case design [76]. Fewer than $0.01 \%$ of random locations were cast within the same pixel as used locations; thus contamination was not a concern [77].

2.4. Spatial Analysis: Mountain Lions. We deployed four models of GPS collars on mountain lions: Lotek Wireless 4400s $(n=9)$, Televilt Simplex $(n=23)$, Televilt Telus $(n=3)$, and Northstar RASSL Tracker $(n=4$; Northstar Science and Technology, King George, Virginia, USA). Collars were programed to collect 6-10 GPS locations per day; 1-3 locations during midday (10:00-14:00), and 57 locations during crepuscular and nighttime hours (18:0006:00). Risk of predation by mountain lions was indexed by two measures: the distribution of locations of GPS collars from mountain lions active (and likely hunting) within winter 
range of bighorn sheep and the distribution of locations where bighorn sheep were killed or cached by mountain lions.

We defined locations of "active" mountain lions by selecting locations of GPS collars not associated with cached prey or resting places [78]. Clusters of locations characteristic of cached prey or of resting sites, where mountain lions were not actively hunting, were selected with a $\mathrm{C}++$ program (see Supplement 1; ClusterDetector in Supplementary Material available online at http://dx.doi.org/10.1155/2015/357080), which identified clusters of locations based on temporal and spatial parameters. We set the spatial tolerance to $<200 \mathrm{~m}$ within $\leq 6$ days [79]. We retained only one GPS location for each cluster, to avoid pseudoreplication of locations where inactive mountain lions were likely resting [78], or feeding at a kill [59] and thus not actively hunting. We retained all GPS locations (i.e., 2D and 3D locations of all DOP values) to increase the sample of locations of active mountain lions for calculation of utilization distributions.

Locations where mountain lions killed and cached bighorn sheep $(n=39)$ were identified by evaluating clusters of locations from GPS collars deployed on mountain lions $(n=10)$ [79], investigating mortality signals from collared bighorn sheep $(n=13)$, or from kills encountered while following mountain lion tracks or trailing hounds that located a carcass $(n=16)$. Mortalities of bighorn sheep were assigned as "probable" kills by mountain lions when two or more of these characteristics were present: tracks, drag marks, or feces from mountain lions; puncture wounds or hematomas on the neck; presence of an intact rumen; ribs cleanly cut as by carnassial teeth; and caching of the carcass. Where possible, location of a kill site was marked with a hand-held GPS (Model 12 XL, Garmin International Inc., Olathe, Kansas, USA); however, in most instances, location of the cached carcass rather than the kill site was recorded, because tracks, drag marks, or other kinds of evidence (e.g., blood, hair) at the kill location often were not detectable on granitic substrates.

We created one risk surface from all locations of GPS collars of active mountain lions within winter range of bighorn sheep and a second risk surface from all locations where bighorn sheep were killed or cached by mountain lions; these were based on adaptive-kernel utilization distributions (Home Range Tools for ArcGIS; [80]) with a smoothing factor of $80 \% h_{\text {ref }}$ that prevented polygons within home ranges from fragmenting [66]. Risk values from utilization distributions were scaled from 1 to 99 and areas within the winter range that fell outside of the $1 \%$ utilization distribution for each risk surface were assigned the minimum value of 1 .

2.5. Spatial Analysis: Topography. We obtained elevation data from 1:24,000-scale, $10 \mathrm{~m}$ digital elevation models (DEM; US Geological Society Seamless Data Server: http://seamless.usgs.gov, accessed 27 September 2010). Average incident solar radiation was quantified monthly in winter (January-April) by calculating potential relative radiation, a measure incorporating monthly changes in solar elevation, as well as local shading because of topography [81]. We calculated potential relative radiation as the sum of hillshade values for each daylight hour on the 15th day of each month, with solar azimuth and elevation values for that hour (NOAA Solar Calculator: http://www.esrl.noaa.gov/gmd/ grad/solcalc/). Terrain ruggedness was calculated with the terrain diversity index of Nicholson et al. [12]. We also calculated a binary value for convexity by comparing the elevation at a location with the average elevation of $10-\mathrm{m}$ pixels within the evaluation radius, differentiating concave drainages (convexity $=0$ ), which are less likely to be used by bighorn sheep, from convex ridgelines (convexity $=1$ ); those features could have an identical terrain-ruggedness value. Positive convexity over $15-30 \mathrm{~m}$ likely represents outcroppings or ridges providing enhanced visibility for bighorn sheep [24] or, more generally, escape terrain at the microhabitat scale of the location of the animal, whereas negative convexity at the $100-150 \mathrm{~m}$ macroscale probably indicates proximity to steep slopes and rock outcroppings constituting escape terrain. Terrain ruggedness and convexity were calculated over radii of $15,20,30,100$, and $150 \mathrm{~m}$ to elucidate the scale at which bighorn sheep selected for rugged and convex escape terrain [82-84].

2.6. Remote Sensing. We obtained daily data for precipitation from 1949 to 2009 from the Bishop Airport, California, USA, (Western Regional Climate Center: http://wrcc.dri.edu/) located $25 \mathrm{~km}$ from winter range at Wheeler Ridge and $42 \mathrm{~km}$ from winter range at Mount Baxter. Data were summarized by calculating cumulative precipitation for each date, beginning 1 October, for the water year (1 October-30 September), total precipitation for each water year, and departure from the 60year average (1949-2009) for each water year.

We used image analysis software (Imagine 2010, ERDAS, Inc., Atlanta, Georgia, USA) to classify vegetation types and calculate vegetation and snow-cover indices from cloud-free Landsat 5 Thematic Mapper (TM; $n=50$; 1987-1994 and 2002-2009) and Landsat 7 Enhanced Thematic Mapper Plus (ETM+ $n=7$ 2002-2003; collectively denoted herein as "TM" imagery; USGS; http://earthexplorer.usgs.gov; accessed 2-18 August 2011). Downloaded images were used without postprocessing, with geometric and radiometric correction by the USGS Earth Resources Observation and Science (EROS) data center. Imagery employed Level 1 Terrain Correction, which used both ground control points for geometric correction and 1-arc second DEMs for orthorectification to remove errors introduced by steep slopes (http://landsat.usgs.gov/descriptions_for_the_levels_of_processing.php). We used 1-m resolution, 4-band aerial imagery from National Agriculture Imagery Program (NAIP) collected in 2009 (http://www.atlas.ca.gov/download.html\#/casil/imageryBaseMapsLandCover/imagery/naip/naip_2009) to generate the rock cover class at the 1-m scale of those aerial photos.

We calculated NDVI and NDSI [51] from digital number values of 31 TM images collected 2002-2009. To minimize inclusion of misleading values of NDVI that measured snow and not vegetation, we classified pixels having NDSI $>0.2$ as snow-covered [52] and nullified the noninformative NDVI values for those pixels. NDVI values were retained for snowfree pixels with NDSI values $\leq 2$. We used the more sensitive 
NDSI threshold of $>0.2$ to maximize sensitivity to snow, described by Dozier [51] as sensitive to detection of alpine snow cover even in shadowed areas in the southern Sierra Nevada. Pixels covered by snow (NDSI > 0.2), tree-shrub, or rock were assumed to have no forage value and assigned the reference NDVI value of zero. The remaining pixels $(n=$ $10,378)$ were categorized into three equal bins as "Low" (1), "Medium" (2), and "High" (3).

Sesnie et al. [85] assessed the utility of remote sensing to evaluate bighorn sheep habitat, concluding that MODIS indices were less degraded by effects of low sun angle and topography than were those from Landsat TM. Heterogeneity of cover at the 250-m scale of the MODIS sensor, however, precluded the use of MODIS to assess third-order selection. Further justification for using Landsat is the availability of TM archives dating from 1982, prior to and spanning the period of "range abandonment" by Sierra Nevada bighorn sheep reported by Wehausen [41]. We obtained vegetation classifications from the US Forest Service Existing Vegetation (EVEG) data layers (http://www.fs.usda .gov/detail/r5/landmanagement/resourcemanagement/?cid= stelprdb5347192; image date; 31 August 2001, accessed 8 November 2010). We combined EVEG layers for conifer forest woodland, hardwood forest woodland, and mixed conifer-hardwood woodland into a single tree layer. The EVEG system did not adequately resolve areas with partial canopy closure, often dominated by mountain mahogany or juniper, which EVEG usually classified as "shrub," a classification that also included much of the open shrub habitat where bighorn sheep foraged. We classified a cover type of open-canopy tree-shrub using Imagine 2010 and a TM image from 1 May 2006, a timing that captured leaf-out of most mountain mahogany, antelope bitterbrush, and mountain whitethorn, characteristic shrubs in this cover class. The resulting classification was validated with $1 \mathrm{~m}$ resolution NAIP imagery collected in 2009. Specificity was $81 \%$ (79/98), and sensitivity 73\% (37/51). We combined our open-canopy, tree-shrub layer and the EVEG tree classification into a composite tree-shrub cover type.

2.7. Forage Tradeoff. We evaluated the potential benefit of migration to low-elevation habitat in winter by assessing differences in the quality and quantity of potential forage, as indexed by NDVI at high elevations $(>3,000 \mathrm{~m})$ and low elevations $(<2,000 \mathrm{~m})$ used by bighorn sheep in winter (Figure 3). These elevations were chosen as convenient thresholds for delineation of areas encompassing the lowest and highest elevations used by bighorn sheep in winter, in which we also had adequate GPS collar data. Only highquality locations $(3 \mathrm{D}, \mathrm{DOP}<10)$ from GPS collars were retained to investigate forage tradeoff. We assumed those locations were representative of the earlier 1987-1995 period, when disuse of low-elevation winter range was reported [41], but for which no telemetry locations were available [50]. Available telemetry data, including an earlier study [86] and recent data from GPS collars, demonstrate use of both high and low elevations in winter, supporting the extrapolation of modern GPS collar data as representative of locations used by bighorn sheep in winter [50].
We used 57 Landsat 5 and Landsat 7 TM scenes (Path 42, Row 34), from 1987 to 1994 and from 2002 to 2009 to assess snow cover (NDSI) and NDVI for pixels used by bighorn sheep in winter. Continuous values for NDVI were calculated after removing TM pixels covered by tree-shrub, rock, or snow (NDSI > 0.2) and, consequently, removed pixels were not indexed for available forage. Within-scene comparisons between high and low elevations were essential to detect the weak signal ( $\leq 0.10 \mathrm{NDVI}$ units) among atmospheric variation (e.g., path radiance, atmospheric attenuation, and aerosolinduced distortion) and variation arising from geometric sun angle-illumination (e.g., solar elevation, azimuth angle, and viewing angle), as well as sensor calibration, all of which can alter NDVI values across images [87]. Our use of both Landsat 5 and Landsat 7 sensors added an additional source of between-image measurement error that was mitigated through within-image comparison.

\subsection{Statistical Analyses. Resource Selection Modeling.-SAS} 9.3 software (SAS Institute, Cary, North Carolina, USA) was used for all statistical analyses. We modeled resource selection functions (RSFs) separately for females and for males [32] but pooled the two study areas to increase inference limits by avoidance of overfitting models to site-specific features. We calculated RSFs using conditional logistic regression (PROC LOGISTIC [88]) in a matched-case design [ 8,76 , $89,90]$, with 10 random locations per used location. Matchedcase design is particularly appropriate for evaluation of RSFs when resources vary over time [91]. Logistic models were fit for the populations of males and females, including a random effect conditioned upon the temporal window of each TM image, thus fitting the model to temporal variation in vegetation quality and quantity (indexed by NDVI) snow cover (indexed by NDSI), and solar radiation.

Prior to analysis, we rescaled variables for elevation, potential relative radiation, and terrain ruggedness at all radii (15-150 m), so that a 1-unit change represented 100 units of the change in the raw variable; thus, odds ratios for those variables indicate the relative odds of selection for each 100unit change in elevation, potential relative radiation, and terrain ruggedness. Mean, SD, and range for those variables in their original scale are provided in Table 5.

2.9. Model Selection and Validation. We retained candidate variables with absolute values of Pearson correlation $<0.60$ and screened for multicollinearity using linear regression diagnostics in SAS 9.3 software [92]. Candidate models included all possible combinations of noncorrelated predictor variables with univariate $P<0.25$ [93]. We calculated Akaike's information criterion adjusted for small sample size $\left(\mathrm{AIC}_{c}\right), \Delta \mathrm{AIC}_{c}$, and Akaike weights for candidate models where $\Delta \mathrm{AIC}_{\mathrm{c}}<4$, indicating substantial informationtheoretic support [94]. We selected among correlated predictor variables by comparing $\triangle \mathrm{AIC}_{\mathrm{c}}$ among models differing only in those correlated predictors. We evaluated the relative importance of variables based on their Akaike importance weights, calculated as the sum of Akaike weight across all models that contained a particular variable [94]. We 


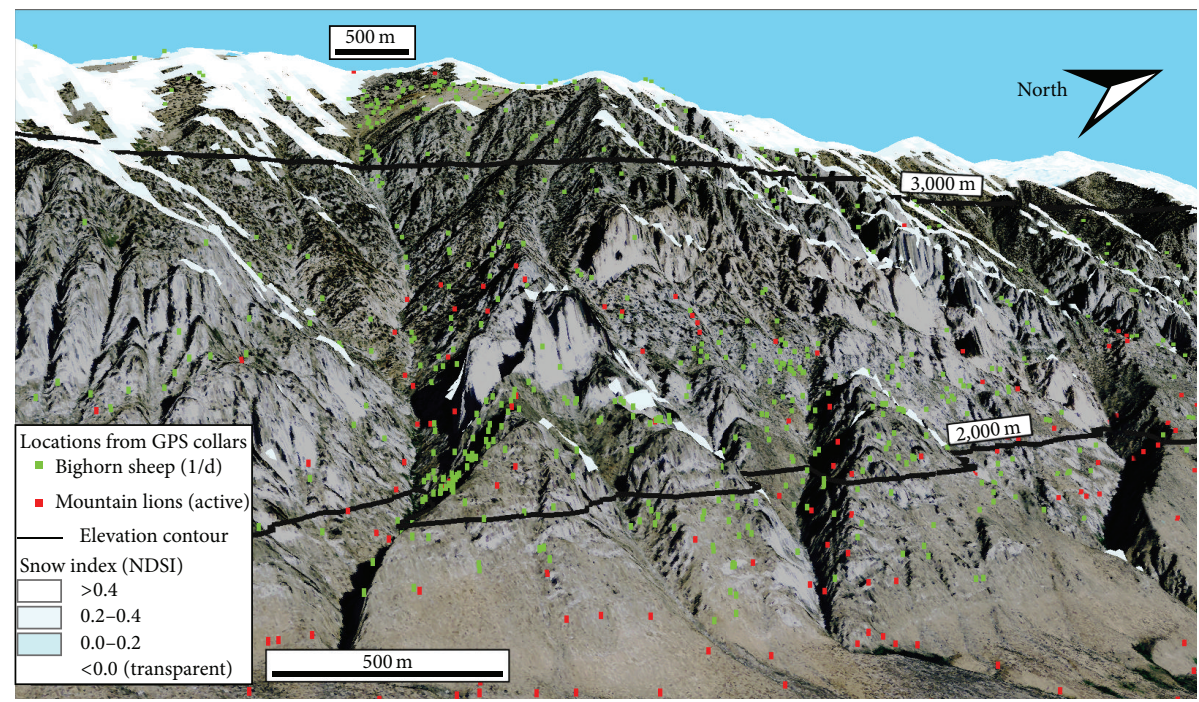

(a)

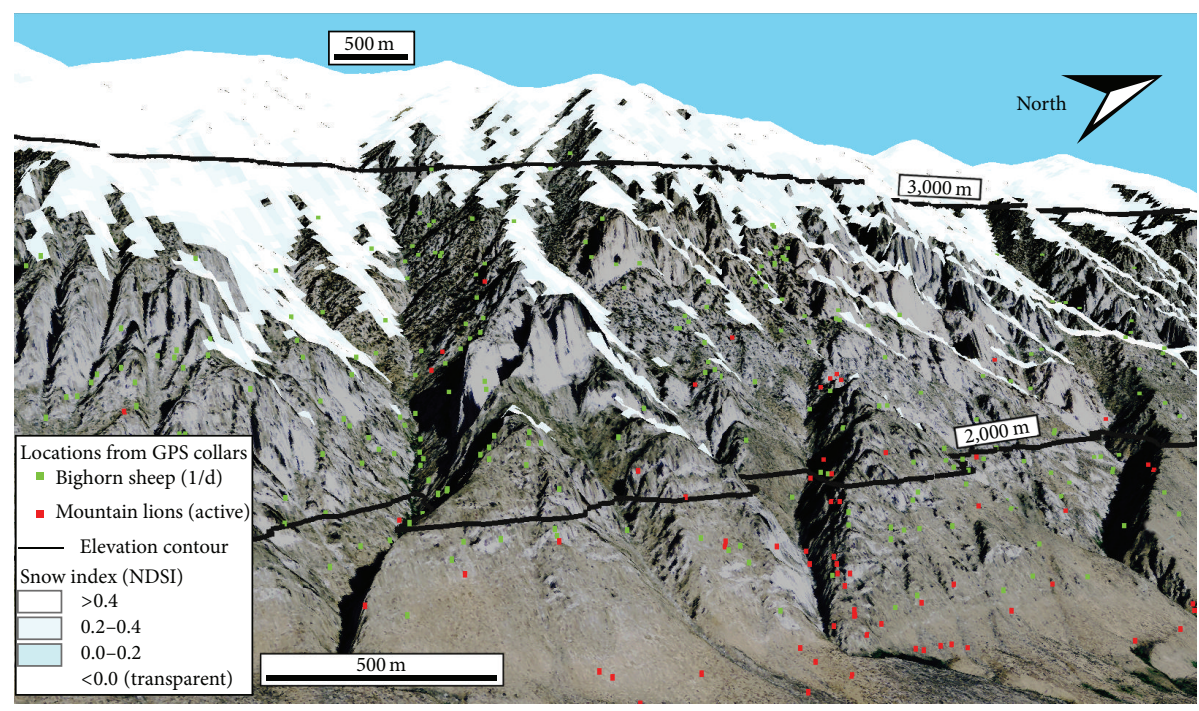

(b)

FIgURE 3: Representative subset of winter habitat for Sierra Nevada bighorn sheep, illustrated by view of Wheeler Ridge from NAIP 2009 aerial image, indicating high elevation $(>3,000 \mathrm{~m})$ and low elevation $(<2,000 \mathrm{~m})$ habitat. Snow cover and locations of bighorn sheep and mountain lions shown for: (a) drought years 2002-2004, 2007 ( $n=1,730$ daily locations of bighorn sheep; $n=1,308$ locations of active mountain lions), with snow cover (NDSI) derived from 12 April 2002 TM image: and (b) above-average precipitation years 2005 and 2006 , $(n=957$ daily locations of bighorn sheep; $n=1,055$ locations of active mountain lions), with snow cover (NDSI) derived from 12 April 2005 TM image. Sierra Nevada, California, USA. Natural color base map is resampled from 1-m native resolution to 10 -m pixel size corresponding to horizontal resolution of 10-m DEM used for 3D visualization. Natural $X, Y$, and $Z$ dimensions preserved (i.e., no stretch is applied to emphasize relief). NDSI from TM image (Path 42, Row 34).

then calculated model-averaged parameter estimates and unconditional standard errors (SE), thereby incorporating both parameter uncertainty and model-selection uncertainty for each predictor variable [95]. We determined if modelaveraged parameter estimates differed from zero by examining whether the unconditional 95\% CI overlapped zero [11].

We used $k$-fold cross validation with five partitions $[76,96-99]$ to evaluate predictive strength of the resource selection functions by withholding a randomly selected $20 \%$ test set of used and random locations and estimating model parameters with the remaining locations. For each of five iterations, the coefficients calculated from the training set were used to calculate RSF values for random locations in the test set, which were then ranked by RSF and assigned to 1 of 10 equal-area bins (i.e., 10-percentile bins). Training-set coefficients were then used to calculate values of RSF for used locations in the test set. Used locations were placed in the bins according to RSF value, and number of locations summed 
for each bin. We regressed the count of used locations in each bin versus the median value from random points and used coefficient of determination, slope, and Spearman rank correlations, averaged among the fivefold validation groups, as diagnostic of the predictive success of each model $[97,99]$.

2.10. Analysis of Forage Tradeoff. We compared NDVI at low elevations $(<2,000 \mathrm{~m})$ with NDVI at high elevations $(>3,000 \mathrm{~m})$ when $\geq 10$ snow-free pixels used by bighorn sheep were available in each elevation category within a TM scene, to ensure an adequate sample of potential forage. Within each TM scene, mean NDVI was calculated among snow-free, lowelevation pixels used by bighorn sheep and among snowfree, high-elevation pixels used by bighorn sheep and not classified as rock or tree-shrub. We calculated NDVI tradeoff as the difference of mean low-elevation NDVI minus mean high-elevation NDVI for each TM image and assigned precipitation to date, total precipitation by water year, and total precipitation in the prior water year to each TM image. We calculated the mean NDVI across 202-1,396 snow-free, lowelevation pixels, and 10-696 snow-free, high-elevation pixels, and calculated NDVI tradeoff as the difference between mean low-elevation NDVI minus mean high-elevation NDVI for 51 TM scenes having $\geq 10$ snow-free pixels at high and low elevation.

We compared the NDVI tradeoff between years of aboveaverage precipitation, with the NDVI tradeoff in those years of below-average precipitation with the nonparametric Wilcoxon signed-rank test for median difference [100], to account for small samples of snow-free pixels present at high elevation during above-average snow years. We explored the relationship among the NDVI tradeoff and measures of precipitation through linear regression.

\section{Results}

Precipitation was highly variable $(\mathrm{CV}=59 \%)$ over the 61 years for which data were available (1949-2009) and exceptionally variable $(\mathrm{CV}=73 \%)$ during 2002-2007, when GPS data were collected from collared bighorn sheep (Figure 9). The driest $(2002 ; 3.5 \mathrm{~cm})$ and third-wettest $(2005 ; 28.5 \mathrm{~cm})$ years on record occurred during that period, demonstrating extremes in snow cover and resource selection by bighorn sheep during drought and wet years (Figure 3).

3.1. Location of Bighorn Sheep and Mountain Lions. We deployed GPS collars on 28 individual bighorn sheep (19 females, 9 males) and collected a mean of 79 days $(S D=49.2$ days, range $=10-172$ days) of locations in winter. Data met the assumption of independence among animals; no pairs of GPS collars deployed on bighorn sheep were associated $(<200 \mathrm{~m})$ for $>25 \%$ of locations. Thirty-nine GPS collars (including replacement collars) were fitted to 24 individual mountain lions (12 females, 12 males; mean number of fixes 1,094, SD $=1,046$, range $=65-4,304$ fixes). Twenty-two mountain lions (12 females and 10 males) used winter ranges of bighorn sheep at Wheeler Ridge $(n=13)$ or Mount Baxter $(n=7)$, and two mountain lions overlapped both winter ranges. Active

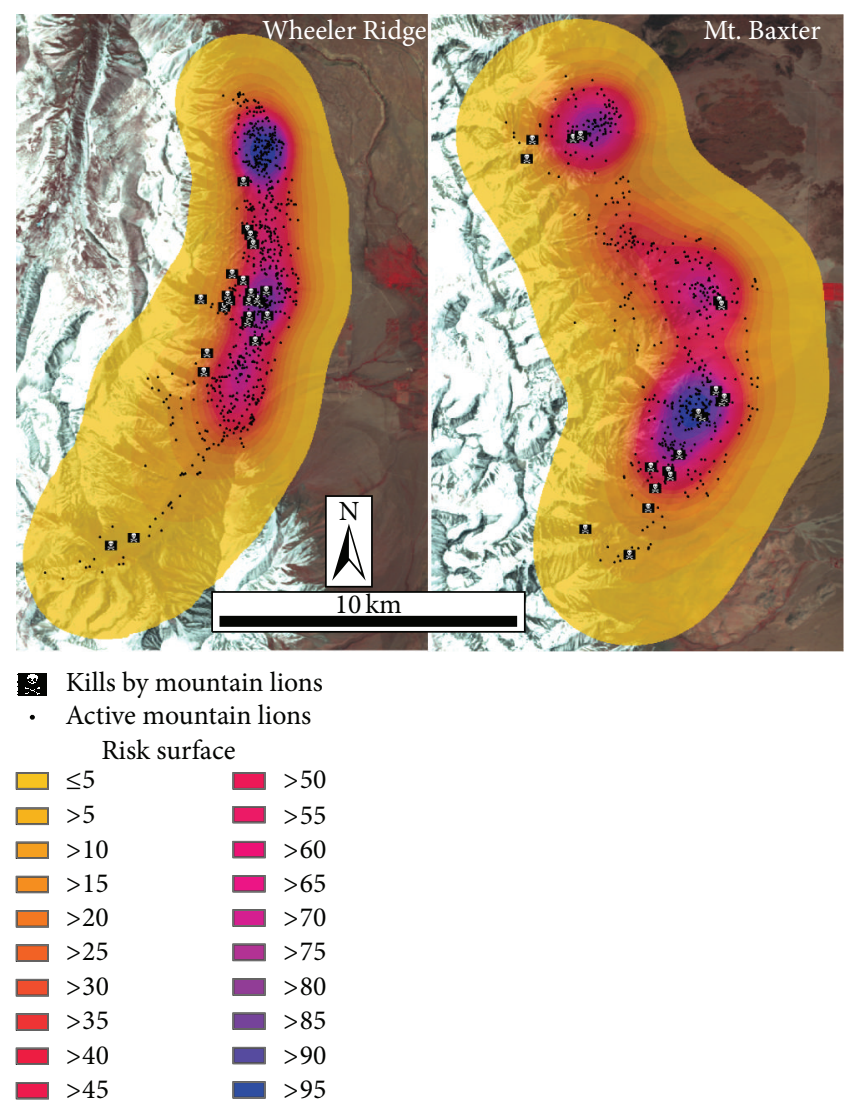

FIgURE 4: Risk surface from probability density functions of active mountain lions (LNRISK), expressed as probability density (199), overlaid by locations where mountain lions were active, and locations where bighorn sheep were killed or cached by mountain lions, Sierra Nevada, California, USA, 2002-2009. Base map is falsecolor TM (bands 4, 3, and 2; Path 42, Row 34, image date 11 March 2005).

locations comprised $47.9 \%$ of 5,453 GPS locations within winter ranges of bighorn sheep.

Risk of predation by mountain lions, quantified by the risk surface of locations of active lions (Figure 4), was negatively correlated with elevation $(r=-0.73$; Table 6); consequently, candidate models included either one, but not both, predictor variables. The risk surface generated from locations where mountain lions killed and cached bighorn sheep was moderately correlated with the risk surface from active lions $(r=0.59$; Figure 4$)$ and elevation $(r=-0.46$; Table 6); accordingly, both variables measuring risk from mountain lions were included as candidate predictors for modeling RSFs.

3.2. Resource Selection Models. Results of RSF modeling indicated selection for the risk surface quantifying probability of mountain lion activity as one of the strongest predictor variables (i.e., Akaike importance weight $=1.0$; Table 2; Figure 5). Although both sexes of bighorn sheep selected for that measure of risk of predation by mountain lions, selection was nearly twice as strong for males $\left(\beta=2.3 \times 10^{-2}\right)$ as for 


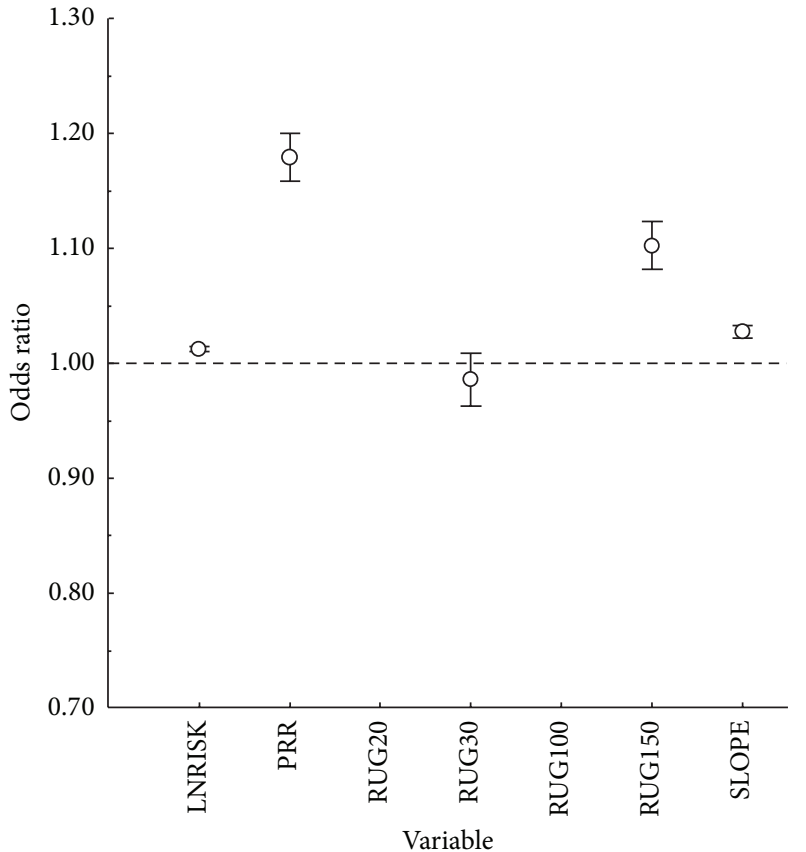

(a) Female continuous

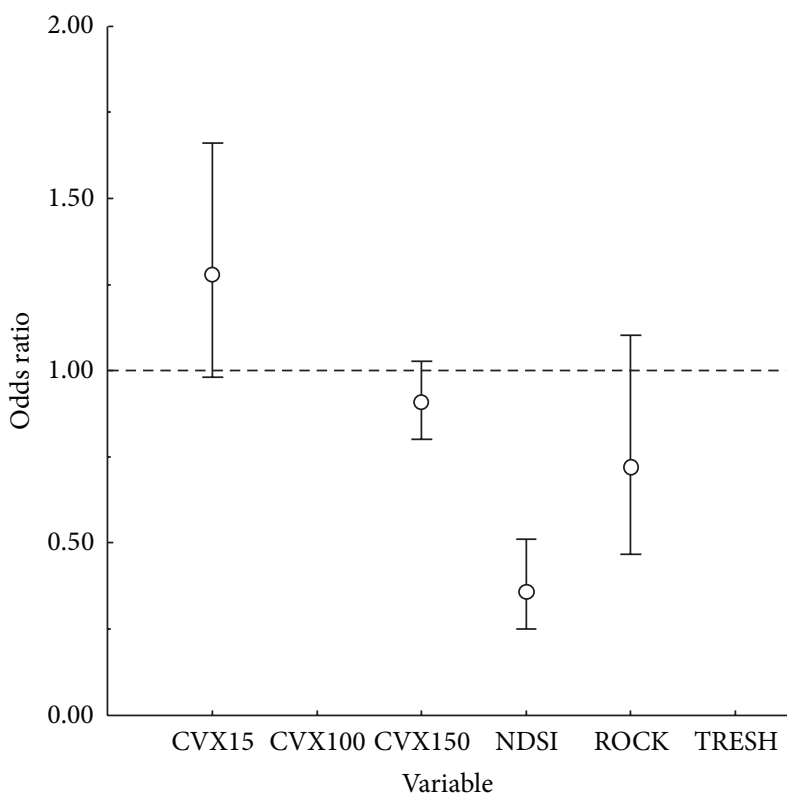

(c) Female NDSI and binary

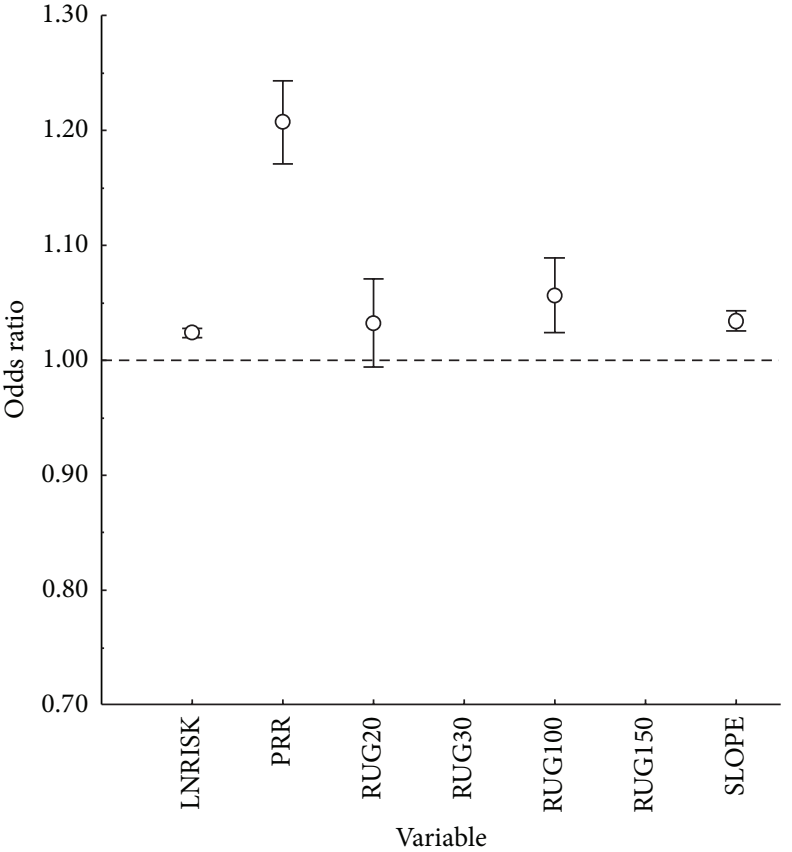

(b) Male continuous

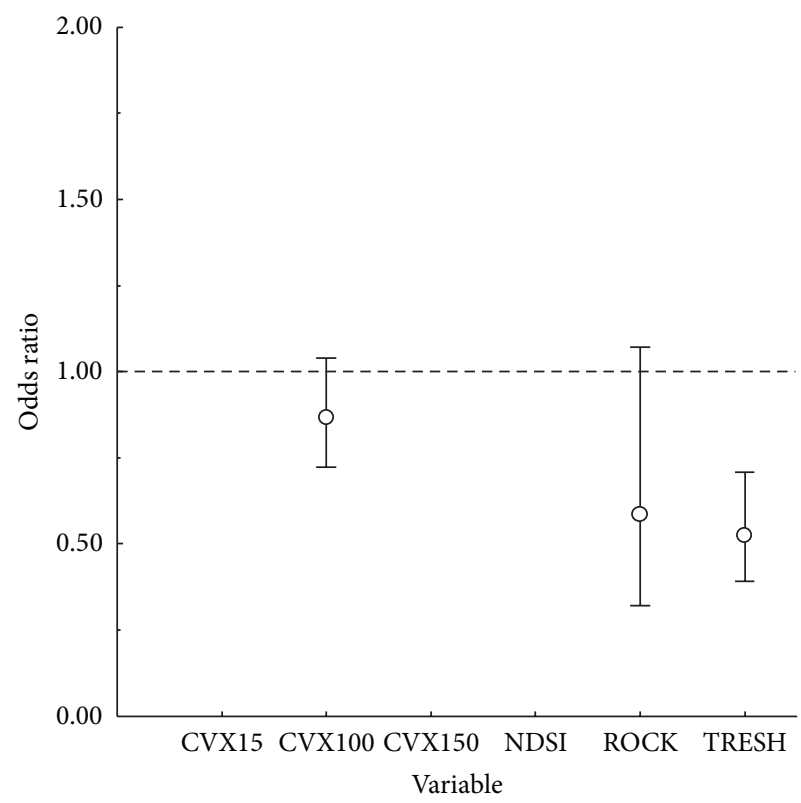

(d) Male NDSI and binary

FIGURE 5: Odds ratios (mean and 95\% CI) from resource selection functions (RSFs) for Sierra Nevada bighorn sheep. Top: continuous predictor variables in best-fitting models of female (a) and male (b) bighorn sheep. Predictors included risk surface from locations of active mountain lions (LNRISK); potential relative radiation (PRR); terrain ruggedness over radii of $20 \mathrm{~m}$ (RUG20), $30 \mathrm{~m}$ (RUG30), 100 m (RUG100), and $150 \mathrm{~m}$ (RUG150); slope (degrees; SLOPE). Bottom: odds ratios for normalized difference snow index (NDSI) and binary variables in bestfitting models of female (c) and male (d) Sierra Nevada bighorn sheep. Predictors included convexity over radii of $15 \mathrm{~m}$ (CVX15), $100 \mathrm{~m}$ (CVX100), and $150 \mathrm{~m}$ (CVX150); rock cover (ROCK); and tree-shrub cover (TRESH), Sierra Nevada, California, USA, 2002-2007. Odds ratios represent the odds of use (where 1 represents 1:1 chance, i.e., no selection) for every one unit change in continuous predictors; LNRISK, SLOPE, and NDSI, and for each 100 unit change in rescaled variables PRR, RUG20, RUG30, RUG100, and RUG150. Odds ratios represent the odds of use, given the positive case for each binary predictor, relative to the absence of the binary predictor for, CVX15, CVX100, CVX150, ROCK, and TRESH. 
females $\left(\beta=1.2 \times 10^{-2}\right)$, with nonoverlapping confidence intervals (Table 2). Selection for areas used by active mountain lions was a better predictor of resource selection during winter than was selection for lower elevations $\left(\triangle \mathrm{AIC}_{\mathrm{c}}=73.7\right.$ for females, $\Delta \mathrm{AIC}_{\mathrm{c}}=124.1$ for males; Table 3$)$.

Additional predictors having the strongest level of support in all candidate models (i.e., Akaike importance weight $=1.0$; Table 2) for the sexes of bighorn sheep included positive selection for areas of high solar radiation, steep slopes, and proximity to rugged terrain, which differed in scale by sex ( $150 \mathrm{~m}$ for females, $100 \mathrm{~m}$ for males; Figure 5). Our methods prevented simultaneous evaluation to determine relative strength of the correlated metrics of ruggedness at $100-\mathrm{m}$ and 150-m scales ( $r=0.87$; Table 6$)$. All candidate models for females included an additional predictor, avoidance of snow (i.e., negative selection for NDSI), whereas candidate models for males indicated avoidance of tree-shrub cover (Akaike importance weight $=0.97$; Table 2; Figure 5).

Less influential variables in the best-fit model included the rock cover class, avoided by both sexes of bighorn sheep, whereas females selected for convexity at the $15-\mathrm{m}$ scale, avoided ruggedness at the $30-\mathrm{m}$ scale, and avoided convexity at the 150-m scale; males selected for ruggedness at the 20$\mathrm{m}$ scale but avoided convexity at the $100-\mathrm{m}$ scale (Figure 5). Masking temporally varying snow cover, static tree-shrub, and rock cover classes for noninformative NDVI values collectively eliminated $49.9 \%$ of 18,240 random locations in our data set. Vegetation conditions, as indexed by NDVI at the remaining $50.1 \%$ of locations, relative to reference areas of rock, snow or tree-shrub, did not enter RSF models. Results of $k$-fold cross validation for RSF models indicated robust fit and substantial accuracy of prediction by models for female and male bighorn sheep (Table 4).

3.3. Evaluation of Forage Tradeoff. Forage tradeoff was evaluated with high-quality locations from GPS collars that identified TM pixels used by bighorn sheep in winter at high elevation ( $n=1,272$ locations; $n=720$ unique TM pixels) and low elevation ( $n=3,830$ locations; $n=1,396$ unique pixels). Values of NDVI pooled across TM images showed high variability and were inconclusive in assessing a potential tradeoff between low-elevation vegetation and high-elevation vegetation condition in drought years compared with wet years (Figure 6(a)). When data were analyzed by comparison of the median of differences between low-elevation habitat and those at high elevations within TM images, however, a significant tradeoff in NDVI was demonstrated for years of above-average precipitation compared with years of below average precipitation (Figure 6(b); Wilcoxon statistic $=589$, $P<0.001)$. The best single predictor of the magnitude of an NDVI tradeoff was precipitation to date (Figure 7). Additional variation was explained $\left(R^{2}\right.$ adjusted $\left.=0.51\right)$ by addition of precipitation in the prior water year, yielding the linear equation: NDVI tradeoff $=0.017+0.0030 \times$ (precipitation to date $)+0.0013 \times($ precipitation in prior water year).

\section{Conclusions}

4.1. Hypothesis I-A: Resource Selection Was Influenced by Direct Risk of Predation. The hypothesis predicting an influence by direct risk of predation on resource selection by male and female Sierra Nevada bighorn sheep (Table 1) was supported, but in a direction opposite to that predicted under the predation risk hypothesis. One of the strongest positive predictors of resource selection by bighorn sheep was a measure of direct risk of predation by mountain lions; all candidate models (i.e., Akaike importance weight $=1.0$ ) for female and for male bighorn sheep included selection for proximity to locations where mountain lions were active (Figure 5; Table 2), and likely hunting [78]. This outcome may have resulted from bighorn sheep selecting areas with suitable forage and escape terrain and mountain lions hunting in areas where mule deer overlapped winter range of bighorn sheep $[50,56]$. This outcome also was consistent with the determination by Pierce et al. [101] that the distribution of mountain lions was predicated upon the distribution of mule deer, their primary prey, available to hunt. Positive selection for areas of high use by mountain lions was also reported by Greene [102], in her assessment of a cohort of Sierra Nevada bighorn sheep collared in 2007-2008 on the Mount Baxter winter range.

Challenges to assessing the influence of direct risk of predation included the choice of appropriate spatial and temporal scales. We quantified direct risk of predation with a static probability density function generated from the aggregate of locations of active mountain lions over eight winters. Such a metric allowed evaluation of resource selection by bighorn sheep relative to generalized predation risk but did not attempt to quantify short-term responses to transient risk, which are evident in correlation of locations of bighorn sheep and mountain lions, when viewed in a temporal window of days (J. T. Villepique, unpublished data). Although mountain lions are protected in California [103], a total of three mountain lions were removed from the two winter ranges, which were managed under identical protocols, after those animals were determined to have killed endangered bighorn sheep. Removal of three mountain lions identified as a threat to endangered bighorn sheep may have reduced the influence of those mountain lions more likely to hunt bighorn sheep on the probability distribution generated from GPScollared mountain lions.

4.2. Hypothesis I-B: Resource Selection Was Influenced by Indirect Risk of Predation. The hypothesis positing influence of indicators of indirect risk of predation was supported by selection of rugged topographic features conferring protection from some predators. All models of RSF for the sexes indicated significant selection for steep slopes and selection for proximity to escape terrain (Table 2; Figure 5). Differences in scale among the sexes of bighorn sheep likely were related to group size $[23,29,104]$. The indirect risk hypothesis received additional support from improved model fit when measures of ruggedness and convexity in immediate proximity to the animal were added to RSFs (Table 2, Figure 5). An unexpected result was that females 
TABLE 2: Model-averaged parameter estimates, 95\% confidence intervals (CI), and Akaike importance weights (AIW) for predictor variables included in best-fitting model of RSF for female and male Sierra Nevada bighorn sheep, Sierra Nevada, California, USA, 2002-2007. Asterisks adjacent to parameter estimates indicate $95 \%$ CIs do not overlap zero.

\begin{tabular}{|c|c|c|c|c|c|c|c|c|}
\hline \multirow{2}{*}{ Variable } & \multicolumn{4}{|c|}{ Female } & \multicolumn{4}{|c|}{ Male } \\
\hline & Estimate & Lower CI & Upper CI & AIW & Estimate & Lower CI & Upper CI & AIW \\
\hline CVX15 & 0.18 & $-3.4 \times 10^{-2}$ & 0.40 & 0.76 & - & - & - & - \\
\hline CVX100 & - & - & - & - & $-1.1 \times 10^{-2}$ & $-3.4 \times 10^{-2}$ & $1.3 \times 10^{-2}$ & 0.08 \\
\hline CVX150 & $-3.0 \times 10^{-2}$ & $-8.5 \times 10^{-2}$ & $2.5 \times 10^{-2}$ & 0.29 & - & - & - & - \\
\hline LNRISK & $1.2 \times 10^{-2^{*}}$ & $9.4 \times 10^{-3}$ & $1.4 \times 10^{-2}$ & 1.00 & $2.3 \times 10^{-2 *}$ & $2.0 \times 10^{-2}$ & $2.7 \times 10^{-2}$ & 1.00 \\
\hline NDSI & $-1.03^{*}$ & -1.39 & -0.67 & 1.00 & - & - & - & - \\
\hline PRR & $0.17^{*}$ & 0.15 & 0.18 & 1.00 & $0.18^{*}$ & 0.15 & 0.21 & 1.00 \\
\hline ROCK & -0.12 & -0.33 & $9.4 \times 10^{-2}$ & 0.35 & -0.35 & -0.80 & 0.11 & 0.63 \\
\hline RUG20 & - & - & - & - & $8.4 \times 10^{-2}$ & $-7.3 \times 10^{-3}$ & $2.4 \times 10^{-2}$ & 0.27 \\
\hline RUG30 & $-1.3 \times 10^{-3}$ & $-4.4 \times 10^{-3}$ & $1.8 \times 10^{-3}$ & 0.09 & - & - & - & - \\
\hline RUG100 & - & - & - & - & $6.1 \times 10^{-2 *}$ & $3.1 \times 10^{-2}$ & $9.2 \times 10^{-2}$ & 1.00 \\
\hline RUG150 & $9.4 \times 10^{-2^{*}}$ & $7.6 \times 10^{-2}$ & 0.11 & 1.00 & - & - & - & - \\
\hline SLOPE & $2.6 \times 10^{-2^{*}}$ & $2.1 \times 10^{-2}$ & $3.2 \times 10^{-2}$ & 1.00 & $3.4 \times 10^{-2^{*}}$ & $2.6 \times 10^{-2}$ & $4.2 \times 10^{-2}$ & 1.00 \\
\hline TRESH & - & - & - & - & $-0.64^{*}$ & -0.94 & -0.33 & 0.97 \\
\hline
\end{tabular}

Note. Variables in RSF models for winter habitat selection by bighorn sheep included convexity over radii of $15 \mathrm{~m}$ (CVX15), 100 $\mathrm{m}$ (CVX100), and 150 $\mathrm{m}$ (CVX150); risk surface from locations of active mountain lions (LNRISK); normalized difference snow index (NDSI); potential relative radiation (PRR); rock cover (ROCK); terrain ruggedness over radii of 20 m (RUG20), 30 m (RUG30), 100 m (RUG100), and 150 m (RUG150); slope (degrees; SLOPE); and tree-shrub cover (TRESH).

TABLE 3: Comparison of resource selection models incorporating risk surface from active mountain lions (LNRISK) with models substituting the correlated predictor elevation (ELEV), for female and male Sierra Nevada bighorn sheep, Sierra Nevada, California, USA, $2002-2007$. Substituted variables denoted by bold type.

\begin{tabular}{lcc}
\hline Model & AIC $_{c}$ & $\Delta$ AIC $_{c}$ \\
\hline Female & 7147.0 & 0.0 \\
CVX15 CVX150 LNRISK NDSI PRR ROCK RUG30 RUG150 SLOPE & 7220.7 & 73.7 \\
CVX15 CVX150 ELEV NDSI PRR ROCK RUG30 RUG150 SLOPE & 3296.9 \\
Male & 3421.0 & 0.0 \\
CVX100 LNRISK PRR ROCK RUG20 RUG100 SLOPE TRESH & 124.1 \\
CVX100 ELEV PRR ROCK RUG20 RUG100 SLOPE TRESH & \\
\hline
\end{tabular}

Note. Variables in RSF models for winter habitat selection by bighorn sheep included convexity over radii of $15 \mathrm{~m}$ (CVX15), $100 \mathrm{~m}$ (CVX100), and $150 \mathrm{~m}$ (CVX150); risk surface from locations of active mountain lions (LNRISK); normalized difference snow index (NDSI); potential relative radiation (PRR); rock cover (ROCK); terrain ruggedness over radii of 20 m (RUG20), 30 m (RUG30), 100 m (RUG100), and $150 \mathrm{~m}$ (RUG150); slope (degrees; SLOPE); and tree-shrub cover (TRESH).

TABLE 4: Results of 5-fold cross validation of resource selection functions for female and male Sierra Nevada bighorn sheep, 2002-2007, indicating slope, coefficient of determination $\left(r^{2}\right)$, and Spearman rank correlation $\left(r_{s}\right)$, Sierra Nevada, California, USA, 2002-2007.

\begin{tabular}{lccc}
\hline Model & Slope & $r^{2}$ & $r_{s}$ \\
\hline Female & 0.19 & 0.95 & 0.96 \\
Male & 0.05 & 0.81 & 0.92 \\
\hline
\end{tabular}

selected against ruggedness at the intermediate $30 \mathrm{~m}$ scale, albeit with weak evidence (Akaike importance weight $=0.09$ ). Rachlow and Bowyer [13] similarly documented selection of less-rugged microhabitats, proximate to rugged escape terrain, by female Dall's sheep (O. dalli). Proximity to escape terrain (represented by the strongly selected ruggedness within $150 \mathrm{~m}$ ) likely mitigated indirect predation risk for female bighorn sheep in our study (Table 2, Figure 5). A remaining corollary supporting the indirect risk hypothesis was the avoidance of tree-shrub cover by males although, surprisingly, not by females, possibly because availability of tree-shrub cover was lower at midelevations occupied by females compared with riparian and shrub areas proximate to the lowest elevations, used exclusively by males. Another unexpected outcome was avoidance of rock cover by both sexes. This outcome was best explained by inclusion of large areas of steep cliffs inaccessible to bighorn sheep in that cover class.

Evaluation of resource selection by bighorn sheep, relative to habitat-mediated, indirect risk of predation, presented challenges related to biases inherent in GPS collars, which are less likely to obtain high-quality fixes when proximity to escape terrain blocks available sky. Difficulties also arose in differentiating qualitative differences within the rock cover class, present at only $1.7 \%$ of random points (Table 5). Rock cover was associated with steep escape terrain used by 
TABle 5: Description of candidate variables used to model resource selection by Sierra Nevada bighorn sheep and descriptive statistics for 18,240 random locations, Sierra Nevada, California, USA, 2002-2007. Values reported for binary variables are counts.

\begin{tabular}{|c|c|c|c|c|c|}
\hline Variable & Description & Mean & $\mathrm{SD}$ & Min. & Max \\
\hline \multicolumn{6}{|c|}{ Continuous variables } \\
\hline KLRISK & Risk surface, locations of bighorn sheep kills & 33.66 & 26.46 & 1.00 & 99.00 \\
\hline LNRISK & Risk surface, locations of active mountain lions & 28.83 & 26.86 & 1.00 & 99.00 \\
\hline NDSI & Normalized difference snow index & $-2.46 \times 10^{-2}$ & 0.33 & -0.67 & 0.90 \\
\hline NDVI & Normalized difference vegetation index & -0.15 & 0.14 & -0.44 & 0.59 \\
\hline ELEV & Elevation in meters & $2.47 \times 10^{3}$ & 600.59 & $1.29 \times 10^{3}$ & $4.01 \times 10^{3}$ \\
\hline SLOPE & Slope in degrees & 33.33 & 14.31 & 0.00 & 80.47 \\
\hline PRR & Potential relative radiation & $1.17 \times 10^{3}$ & 532.86 & 0.00 & $1.98 \times 10^{3}$ \\
\hline \multicolumn{6}{|c|}{ Terrain ruggedness } \\
\hline \multicolumn{6}{|c|}{ (over specified radius) } \\
\hline RUG15 & $15 \mathrm{~m}$ & 230.40 & 195.47 & 0.00 & $2.70 \times 10^{3}$ \\
\hline RUG20 & $20 \mathrm{~m}$ & 411.49 & 267.63 & 0.00 & $3.39 \times 10^{3}$ \\
\hline RUG30 & $30 \mathrm{~m}$ & 561.58 & 309.56 & 0.00 & $2.68 \times 10^{3}$ \\
\hline RUG100 & $100 \mathrm{~m}$ & $9.93 \times 10^{2}$ & 390.77 & 86.63 & $3.77 \times 10^{3}$ \\
\hline RUG150 & $150 \mathrm{~m}$ & $1.14 \times 10^{3}$ & 404.37 & 144.56 & $3.44 \times 10^{3}$ \\
\hline \multicolumn{6}{|c|}{ Binary variables (frequency) } \\
\hline ROCK & Classified from NAIP 2009 image & 325 & - & - & - \\
\hline TRESH & Tree and mixed shrub classification & $6.66 \times 10^{3}$ & - & - & - \\
\hline \multicolumn{6}{|c|}{ Convexity (over specified radius) } \\
\hline CVX15 & $15 \mathrm{~m}$ & $1.69 \times 10^{4}$ & - & - & - \\
\hline CVX20 & $20 \mathrm{~m}$ & $1.57 \times 10^{4}$ & - & - & - \\
\hline CVX30 & $30 \mathrm{~m}$ & $1.44 \times 10^{4}$ & - & - & - \\
\hline CVX100 & $100 \mathrm{~m}$ & $1.10 \times 10^{4}$ & - & - & - \\
\hline CVX150 & $150 \mathrm{~m}$ & $1.02 \times 10^{4}$ & - & - & - \\
\hline
\end{tabular}

TABLE 6: Pearson correlation coefficients for candidate variables at 18,240 random locations used to model resource selection by Sierra Nevada bighorn sheep, Sierra Nevada, California, USA, 2002-2007. Absolute value of $r>0.60$ denoted by bold type.

\begin{tabular}{|c|c|c|c|c|c|c|c|c|c|c|c|c|c|c|}
\hline Variable & 1 & 2 & 3 & 4 & 5 & 6 & 7 & 8 & 9 & 10 & 11 & 12 & 13 & 14 \\
\hline \multicolumn{15}{|c|}{ Biotic and remotely sensed variables } \\
\hline (1) KLRISK & - & & & & & & & & & & & & & \\
\hline (2) LNRISK & 0.59 & - & & & & & & & & & & & & \\
\hline (3) NDSI & -0.33 & -0.44 & - & & & & & & & & & & & \\
\hline (4) ROCK & 0.09 & 0.07 & -0.04 & - & & & & & & & & & & \\
\hline (5) TRESH & -0.08 & -0.19 & 0.09 & -0.08 & - & & & & & & & & & \\
\hline \multicolumn{15}{|c|}{ Topographic variables } \\
\hline (6) ELEV & -0.46 & -0.73 & 0.57 & -0.04 & 0.14 & - & & & & & & & & \\
\hline (7) SLOPE & 0.04 & -0.14 & 0.11 & 0.11 & -0.02 & 0.34 & - & & & & & & & \\
\hline (8) PRR & 0.02 & 0.07 & -0.15 & -0.02 & -0.06 & -0.06 & -0.19 & - & & & & & & \\
\hline (9) RUG20 & 0.05 & -0.04 & 0.05 & 0.05 & -0.03 & 0.17 & 0.37 & -0.11 & - & & & & & \\
\hline (10) RUG100 & 0.03 & -0.11 & 0.12 & 0.08 & -0.06 & 0.29 & 0.55 & -0.15 & 0.49 & - & & & & \\
\hline (11) RUG150 & 0.02 & -0.12 & 0.13 & 0.08 & -0.06 & 0.29 & 0.53 & -0.14 & 0.44 & 0.87 & - & & & \\
\hline (12) CVX15 & -0.01 & 0.03 & -0.03 & -0.02 & 0.01 & -0.05 & -0.20 & 0.12 & -0.18 & -0.15 & -0.13 & - & & \\
\hline (13) CVX100 & 0.00 & 0.05 & -0.05 & -0.02 & 0.02 & -0.07 & -0.15 & 0.10 & -0.11 & -0.18 & -0.20 & 0.17 & - & \\
\hline (14) CVX150 & 0.02 & 0.04 & -0.05 & 0.00 & 0.01 & -0.03 & -0.07 & 0.08 & -0.05 & -0.11 & -0.15 & 0.11 & 0.79 & - \\
\hline
\end{tabular}

Note. Variables in RSF models for winter habitat selection by bighorn sheep included convexity over radii of $15 \mathrm{~m}$ (CVX15), 100 m (CVX100), and 150 m (CVX150); risk surface from locations of active mountain lions (LNRISK); normalized difference snow index (NDSI); potential relative radiation (PRR); rock cover (ROCK); terrain ruggedness over radii of 20 m (RUG20), 30 m (RUG30), 100 m (RUG100), and $150 \mathrm{~m}$ (RUG150); slope (degrees; SLOPE); and tree-shrub cover (TRESH). 


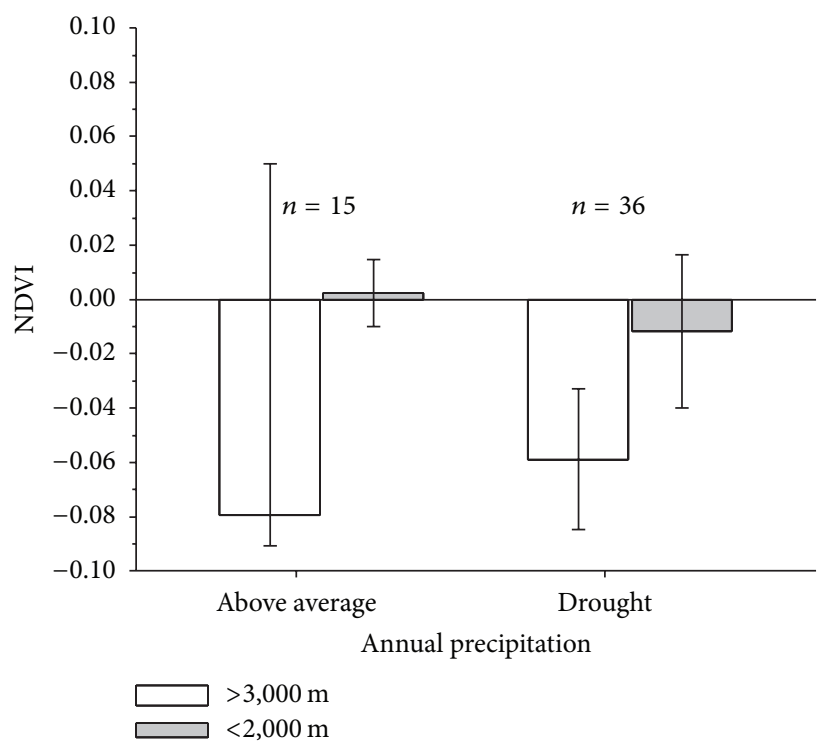

(a)

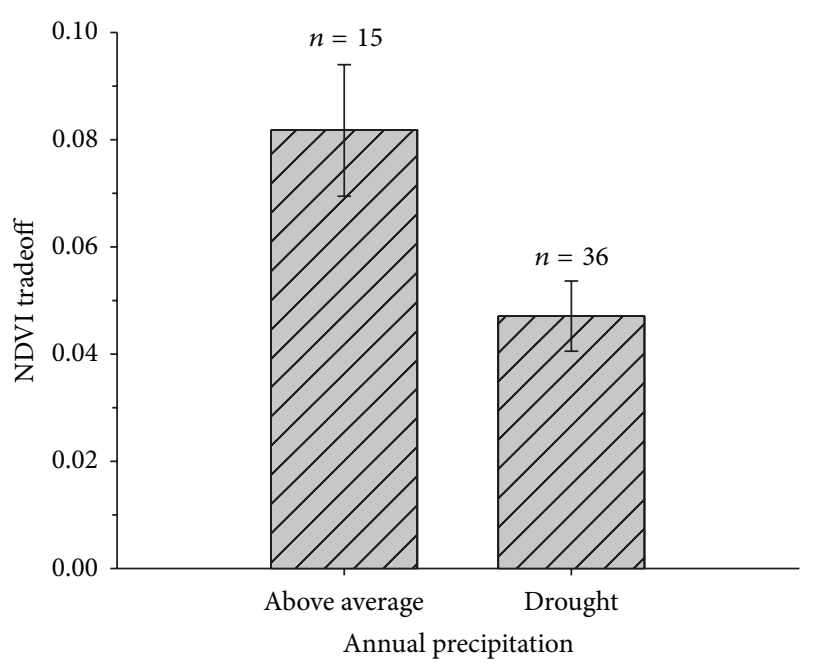

(b)

FIGURE 6: Comparison of NDVI from Landsat TM in areas used by bighorn sheep in winter (January-April) at high elevations ( $>3000 \mathrm{~m}$ ) and low elevations $(<2000 \mathrm{~m}$ ), in above-average and below-average precipitation years; (a) values of NDVI (mean and $95 \% \mathrm{CI}$ ) at high and low elevations pooled across TM scenes, and (b) tradeoff of vegetation condition at low versus high elevations, measured as difference between NDVI at low elevation minus NDVI at high elevation (mean and 95\% CI) within each TM scene, Sierra Nevada, California, USA, 1987-1994 and 2002-2009.

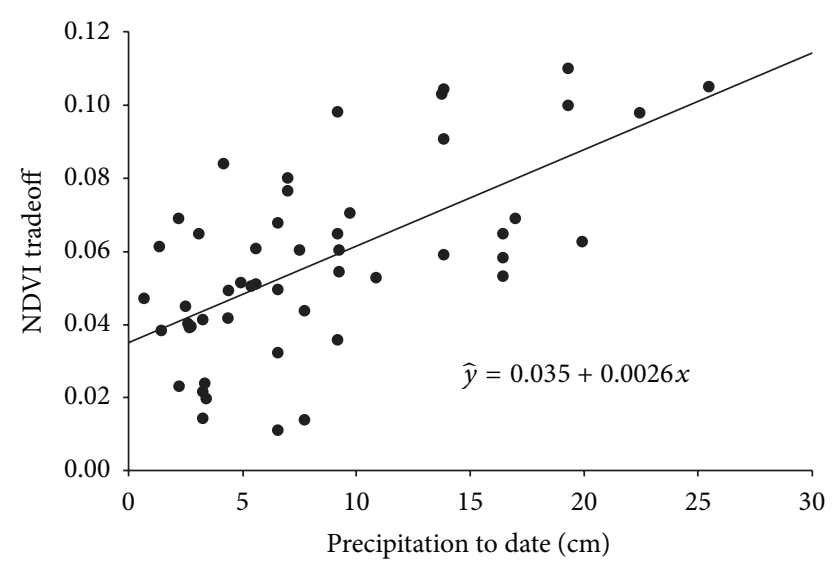

FIGURE 7: Relationship between precipitation and NDVI tradeoff $\left(r^{2}=0.40 ; n=51\right)$. Addition of total precipitation of the prior water year $\left(\mathrm{H}_{2}\right.$ OprevYr; October 1-September 30) produced a better model fit $\left(\triangle \mathrm{AIC}=9.6 ; R_{\mathrm{adj}}^{2}=0.51 ; n=51\right) ; \hat{y}=0.017+0.0030 \times$ $\mathrm{H}_{2}$ OtoDate $+0.0013 \times \mathrm{H}_{2}$ OprevYr.

bighorn sheep in our study area but also included massive granitic plutons, favored by human technical rock climbers, which were too steep for bighorn sheep to traverse. Our analysis of resource selection also did not account for effects of sociality, specifically group size, an important determinant of foraging decisions under risk of predation in bighorn sheep $[23,29,104]$.

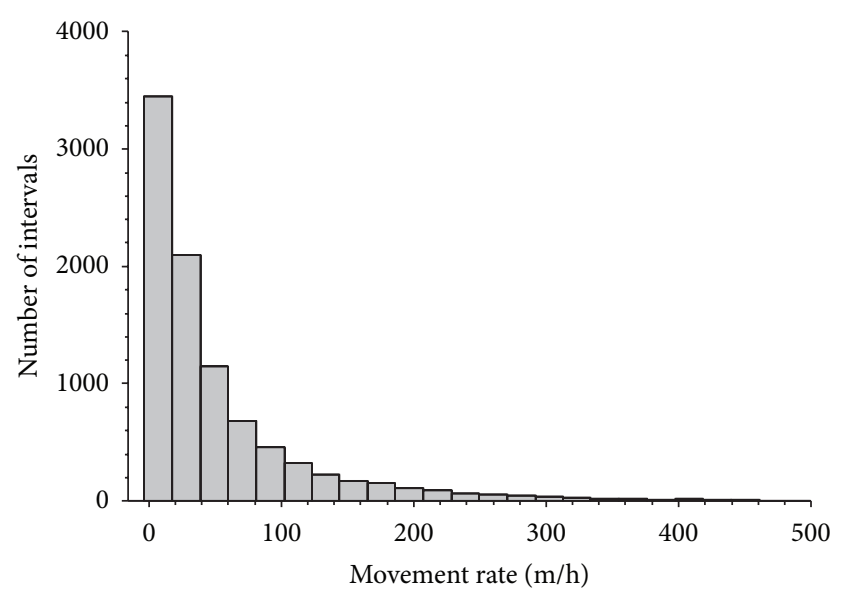

FIGURE 8: Hourly winter (January-April) movement rates by Sierra Nevada bighorn sheep, California, USA, 2002-2007. Mean interval between daily GPS locations was GPS $6.5+/-0.1 \mathrm{~h}$ (CI; range 1-36 h) for $3 \mathrm{D}$ locations with DOP $<10$ ( $n=9,332$ intervals).

4.3. Hypothesis II: Habitat Selection Is Influenced by Forage Availability. The forage-availability hypothesis was supported by significant selection in all candidate models for potential relative radiation, a proxy for insolation that is correlated with patterns of vegetation growth [81]. Similarly, females, but not males, avoided snow cover (i.e., selected for negative NDSI), as predicted by the forage-availability hypothesis. Models of resource selection did not, however, 


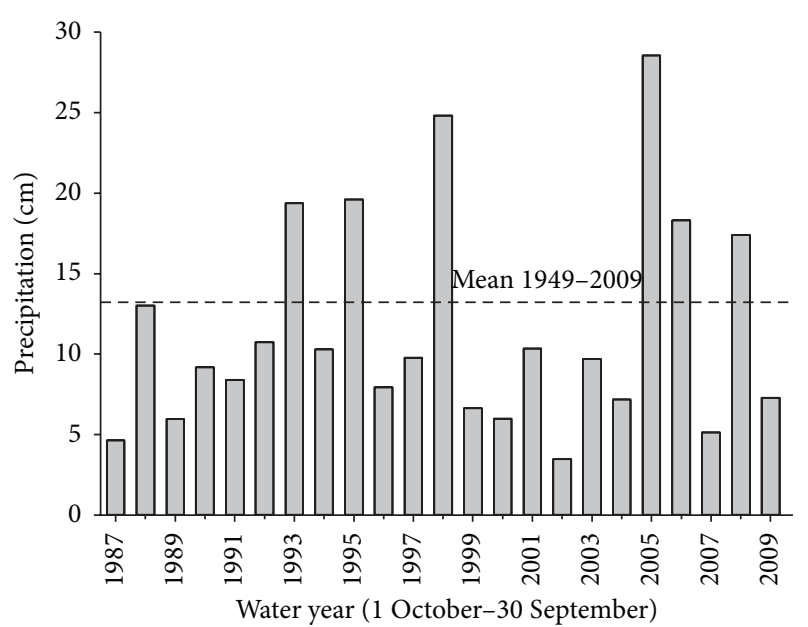

FIGURE 9: Annual precipitation and long-term mean (dashed horizontal line), Bishop, California, USA, 1987-2009.

include NDVI as an informative predictor. Despite shortcomings in the application of TM imagery to evaluate forage in a use-versus-availability model at the scale of third-order selection, we successfully used radiance values from TM sensors to elucidate strong avoidance of snow cover by females (i.e., females selected for negative NDSI). Males, however, sometimes remained in snow-covered, highelevation areas rather than moving to lower elevations ( $\mathrm{J}$. T. Villepique, personal observations), as was typical for females. This divergent strategy relative to snow was likely related to the larger body size of males [17], allowing movement and foraging in snow at a lower cost, relative to that for smallerbodied females. Male bighorn sheep in the Sierra Nevada selected areas with significantly higher biomass of shrubs and consumed significantly greater proportions of sagebrush than did females [29]. Those results are consistent with size differences between male and female digestive systems [2,3], allowing males to use lower-quality woody forage emerging from snow, whereas females would have more difficulty doing so.

Application of satellite NDVI as a metric for spatial and temporal patterns of forage condition within the home range (i.e., third-order selection) [72] was problematic in our study area. A matrix of rock, trees, and snow, where NDVI is noninformative for indexing forage conditions, is common at the spatial scale of available satellite sensors [53]. Those cover types composed $49.9 \%$ of random locations in the TM images we used. Consequently, one-half of pixels were assigned the reference NDVI value of zero, reducing the power to detect selection among the remaining categories of NDVI.

We also did not postprocess TM images to convert raw radiance to reflectance, decreasing the power to detect variation in NDVI. Application of those computationally intensive radiometric corrections for each image entails an added layer of complexity when different sensors are used (e.g., Landsat 5 TM and Landsat 7 ETM+) but is essential for temporal comparisons among images [85]. Our analyses, however, did not make between-image comparisons, because
RSFs were calculated with "used" versus "available" locations conditioned within the common temporal window of the TM scene, thereby reducing the need for corrections.

4.4. Hypothesis III: Tradeoff between Forage versus Risk of Predation Was Reduced during Drought. The hypothesis that drought reduced the forage benefit of migration to low elevations was supported; significantly greater forage benefits resulted from migration to low elevations, where predation risk was highest, in above-average precipitation years compared with the benefits accrued in lower than average precipitation years. Differences in vegetation condition, as indexed by NDVI at low-elevation locations used by bighorn sheep minus NDVI at high-elevation locations used by bighorn sheep, were greatest in years with aboveaverage precipitation (Figure 6(b)). The NDVI tradeoff had a positive linear relationship with quantity of precipitation, with variation largely explained $\left(R^{2}\right.$ adjusted $\left.=0.51\right)$ by cumulative precipitation to date and precipitation the prior water year (Figure 7). The greatest forage benefit of migration, therefore, accrued in sequential years having aboveaverage precipitation, while the lowest benefit was present in consecutive drought years. Conversely, Wehausen [41] concluded that it was the timing, rather than quantity, of precipitation that best correlated with crude protein content in bighorn sheep feces, a proxy for dietary quality [55]. His investigation at Mount Baxter, however, identified a measure of Julian date itself as explanatory of most variation in fecal crude protein [41] $\left(R^{2}=0.57\right)$ and went on to conclude that the best single predictor $\left(R^{2}=0.78\right)$ of fecal crude protein was the number of days elapsed after a substantial precipitation event, termed, "the initiating storm" [105]. The conclusion of the import of timing is suspect, however, as this measure was simultaneously the predictor and predicted, because it was predicated on the occurrence of a storm event of sufficient magnitude (i.e., quantity of precipitation), defined by Wehausen [105] as having, "initiated perennial grass growth."

Locations used by bighorn sheep at high elevation $(>3,000 \mathrm{~m})$ during winter often were covered by snow during years of above-average precipitation, leaving a limited number of snow-free pixels in wind-blown or south-facing areas. Consequently, forage conditions could be indexed by NDVI only in small samples of pixels within TM scenes, yielding additional variation to inherent variability among TM scenes (Figure 6). Application of within-scene comparisons of NDVI, calculated from uncorrected TM radiance, however, nullified temporal variation among NDVI values and allowed comparison of forage tradeoff at static high and low-elevation locations used by bighorn sheep in winter.

4.5. How Results Challenge Predator-Induced Range Abandonment. Our models of RSF by bighorn sheep were robust because of pooling of data among diverse winter ranges at Mount Baxter and Wheeler Ridge and because the years 2002-2007, when data were collected from GPS-collars, were characterized by highly variable precipitation. The driest (2002) and wettest (2005) years since 1987 (Figure 9), when 
Wehausen [41] reported the disuse of low-elevation winter range, occurred during this 6-year span. Wehausen [41] asserted that that use of low-elevation habitat in winter was the rule, unaffected by sequential years of drought, but this is not consistent with our data (Figure 3 ) or past observations [86].

In our study, one of the strongest positive predictors of resource selection by Sierra Nevada bighorn sheep was a measure of direct risk of predation by mountain lions, implicating the activity of mountain lions as a strong predictor of habitat selection by Sierra Nevada bighorn sheep-as posited by Wehausen [41] - but in the opposite direction he suggested. Our analysis demonstrated that rather than abandon preferred habitat, bighorn sheep continued to select the same areas where mountain lions actively hunted in bighorn sheep winter range (Figure 4). We established an alternative to the notion of predator-induced range abandonment [41], by contrasting forage tradeoff in wet versus dry years, revealing significantly reduced benefits of migration to low elevation in drought years (Figure 6). The period of "range abandonment" [41] occurred during 6 consecutive years of drought (19871992 [48]) when snow cover, which was avoided by female bighorn sheep, was sparse at high elevations, and forage benefits of migration to low elevation were significantly lower than in years of above-average precipitation.

Top-down effects, in the form of removal by helicopter capture for translocation, however, may have played a part in the proposed range abandonment in addition to the role of drought as a bottom-up driver. Intensive helicopter capture and removal of 103 bighorn sheep on low elevation winter range at Mount Baxter [41, 106] preceded the 19871995 period of proposed range abandonment [41]. Those captures not only preceded but indeed continued into March 1988, when eight female and three male bighorn sheep were removed [106-109] from the low-elevation range that Wehausen [41] inexplicably defined as then "abandoned." Helicopter capture and translocation was analogous to "direct predation," in that the result of removing animals continuing to use low-elevation winter range was to leave only those animals using a parallel strategy of overwintering at high elevation. Furthermore, while short-term disturbance and flight responses by mountain sheep are well documented in response to low-level helicopter flights [107-110], cumulative effects of repeated helicopter captures are unknown. Repeated helicopter captures that remove conspecifics may alter behavior and elicit responses analogous to those behaviors that mitigate indirect risk of predation, such as avoidance of areas lacking escape terrain, such as those low-elevation areas subject to recurrent helicopter captures. More research is warranted to elucidate behavioral responses to repeated helicopter capture efforts, especially for this endangered taxon.

Our alternative bottom-up hypothesis is supported by data demonstrating a reduced tradeoff by bighorn sheep remaining in snow-free, high-elevation winter habitat during drought years, providing an empirically and theoretically consistent explanation free from the inconsistencies of the predator-induced hypothesis of range abandonment. The bottom-up explanation resolves the inherent conflict between the range abandonment hypothesis and the theory of natural selection: maladaptive behaviors cannot persist in natural systems. Mountain lions share millennia of sympatry with bighorn sheep in North America [111, 112], while hydroclimatic reconstruction demonstrates the nonuniqueness of severe drought [113] over the same period. Thus, evidence does not support a novel set of conditions during the 19871995 period of range abandonment. The proposition that predator-induced range abandonment led to demographic catastrophe fundamentally conflicts with the concept of an evolutionarily stable strategy [15] for resource selection by bighorn sheep under risk of predation by a non-novel predator, the mountain lion. If avoidance of low-elevation winter range was, on average, more costly in terms of nutritional tradeoff, energetic demands, or risks of stochastic mortality inherent to life at high elevation in winter [41], compared with use of low-elevation winter range, such a strategy would experience strong negative selection. Natural selection would favor adoption of a "cheater" strategy, wherein some animals make use of low-elevation winter range and benefit from nutritious forage, while avoiding the perils of life at high elevation. Survivors among these "cheaters" would be strongly selected for. To support the claim that Sierra Nevada bighorn sheep responded to risk of predation by avoiding resources critical to survival and reproduction (e.g., lowelevation habitat in winter) [41] in a manner incompatible with an ESS, extraordinary evidence is necessary but remains lacking.

The bottom-up hypothesis explaining avoidance of lowelevation winter range by bighorn sheep is consistent with the findings of Kucera [114] and Pierce et al. [47], which documented drought-induced reduction in forage available to mule deer wintering in Round Valley, concurrent with the hypothetical predator-induced range abandonment by bighorn sheep [41]. The winter range of the Round Valley mule deer herd overlapped one-third of the winter range of bighorn sheep at Wheeler Ridge [50]. Kucera [114] concluded that drought and limited availability of forage in winter, and not predation by mountain lions, caused the $50 \%$ decline in the number of mule deer wintering adjacent to Wheeler Ridge during 1985-1988. Pierce et al. [47] analyzed long-term demographic and physiological conditions in this mule deer population during 1984-1998 and concluded that bottom-up processes, including prolonged drought, regulated mule deer populations through 1990, when the mule deer population began to recover. Diets of mule deer were dominated by bitterbrush $[114,115]$, also a major forage species for bighorn sheep in winter [18]. Kucera noted an absence of leader growth in bitterbrush during the 1986-1987 drought, as well as heavily browsed shrubs and frequent observations of mule deer feeding while standing on hind legs to reach bitterbrush leaves [114]. In the absence of data refuting drought-induced limits to forage as the major factor responsible for elevational shifts in use of winter range [41], bottom-up processes offer a stronger alternative explanation for declines in Sierra Nevada bighorn sheep.

Investigations into effects of behavioral responses to risk of predation in large herbivores have yielded diverse results, leaving many unanswered questions regarding the 
applicability and magnitude of effects from trait-mediated, indirect interactions in terrestrial systems [116]. Ripple et al. [40] reported a behaviorally mediated trophic cascade (BMTC) in elk in the Greater Yellowstone Ecosystem (hereafter, "Yellowstone"), wherein elk responded to risk of predation by wolves by avoiding risky stands of quaking aspen (Populus tremuloides), thereby reducing herbivory and allowing increased recruitment of aspens. Kauffman et al. [117] evaluated evidence for a BMTC of sufficient magnitude to structure aspen communities in Yellowstone, by assessing foraging by elk under risk of predation by wolves and by comparing historical aspen recruitment inside and outside of exclosures, and concluded that historic precipitation and number of elk, and not a BMTC, explained recruitment of aspen.

Similar conflicting results characterize studies of physiological and demographic costs accrued from energetic demands of antipredator behavior. Creel et al. [38] investigated the correlation between risk of predation by wolves and recruitment in elk in the Yellowstone system, with results indicating a negative relationship between predation risk and reproduction. Middleton et al. [39], conversely, detected no significant effects on pregnancy or body condition in elk subject to frequent proximity and risk of predation by wolves in the Yellowstone system. Those examples illustrate the possibility that conclusions about prey behavior and demography attributed to indirect risk of predation may, upon further examination, be better explained by bottomup processes and direct effects of predation. We find such a bottom-up explanation of resource selection by Sierra Nevada bighorn sheep far more plausible, owing to empirical and theoretical support, than the predator-induced range abandonment hypothesis proffered by Wehausen [41].

\section{Appendix}

See Tables 5 and 6 and Figures 8 and 9.

\section{Conflict of Interests}

The authors declare that there is no conflict of interests regarding the publication of this paper.

\section{Acknowledgments}

The authors thank helicopter pilot S. DeJesus and California Department of Fish and Wildlife capture specialists R. Teagle and T. Glenner, for safe capture of bighorn sheep, and houndsmen J. Davis and J. Ostergard and their assistants V. Davis, M. Kiner, M. Leonard-Cahn, and J. Schmalenberger for their work capturing mountain lions. Additional capture support was provided by personnel from the CDFW Wildlife Investigations Laboratory including B. Gonzales, A. Hunter, K. Jones, L. Konde, J. Schultz., P. Swift, and S. Torres. They thank the many employees and volunteers who helped collect data, including C. Baker, L. Bowermaster, K. Ellis, J. Erlenbach, A. Feinberg, J. Fusaro, D. German, L. Greene, D. Jensen, R. Noles, N. Partridge, P. Partridge, C. Schroeder, A.
Stephenson, and T. Taylor. Discussions with D. Delehanty, J. Kie, R. Long, C. Peterson, T. Stephenson, and J. Wehausen were valuable in guiding this investigation. They thank three anonymous reviewers for helpful comments that improved this paper. This study was funded by California Department of Fish and Wildlife Sierra Nevada Bighorn Sheep Recovery Program, California Deer Association, Desert Bighorn Council, California Chapter of the Wild Sheep Foundation, Department of Biological Sciences at Idaho State University, and the Institute of Arctic Biology at the University of Alaska Fairbanks. This is a contribution from the Sierra Nevada Bighorn Sheep Recovery Program and is Professional Paper 103 from the Eastern Sierra Center for Applied Population Ecology.

\section{References}

[1] P. S. Barboza, K. L. Parker, and I. D. Hume, Integrative Wildlife Nutrition, Springer, Berlin, Germany, 2009.

[2] P. S. Barboza and R. T. Bowyer, "Sexual segregation in dimorphic deer: a new gastrocentric hypothesis," Journal of Mammalogy, vol. 81, no. 2, pp. 473-489, 2000.

[3] P. S. Barboza and R. T. Bowyer, "Seasonality of sexual segregation in dimorphic deer: extending the gastrocentric model," Alces, vol. 37, pp. 275-292, 2001.

[4] N. L. Barten, R. T. Bowyer, and K. J. Jenkins, "Habitat use by female caribou: tradeoffs associated with parturition," Journal of Wildlife Management, vol. 65, no. 1, pp. 77-92, 2001.

[5] J. Berger, "Pregnancy incentives, predation constraints and habitat shifts: experimental and field evidence for wild bighorn sheep," Animal Behaviour, vol. 41, no. 1, pp. 61-77, 1991.

[6] R. T. Bowyer, J. G. Kie, and V. van Ballenberghe, "Habitat selection by neonatal black-tailed deer: climate, forage, or risk of predation?" Journal of Mammalogy, vol. 79, no. 2, pp. 415-425, 1998.

[7] J. M. Fryxell and A. R. E. Sinclair, "Causes and consequences of migration by large herbivores," Trends in Ecology \& Evolution, vol. 3, no. 9, pp. 237-241, 1988.

[8] P. E. Lendrum, C. R. Anderson Jr., R. A. Long, J. G. Kie, and R. T. Bowyer, "Habitat selection by mule deer during migration: effects of landscape structure and natural-gas development," Ecosphere, vol. 3, article 82, 2012.

[9] P. E. Lendrum, C. R. Anderson Jr., K. L. Monteith, J. A. Jenks, and R. T. Bowyer, "Migrating mule deer: effects of anthropogenically altered landscapes," PLoS ONE, vol. 8, no. 5, Article ID e64548, 2013.

[10] S. J. McNaughton, "Ecology of a grazing ecosystem: the Serengeti," Ecological Monographs, vol. 55, no. 3, pp. 259-294, 1985.

[11] K. L. Monteith, V. C. Bleich, T. R. Stephenson et al., “Timing of seasonal migration in mule deer: effects of climate, plant phenology, and life-history characteristics," Ecosphere, vol. 2, no. 4, article 47, 2011.

[12] M. C. Nicholson, R. T. Bowyer, and J. G. Kie, "Habitat selection and survival of mule deer: tradeoffs associated with migration," Journal of Mammalogy, vol. 78, no. 2, pp. 483-504, 1997.

[13] J. L. Rachlow and R. T. Bowyer, "Habitat selection by Dall's sheep (Ovis dalli): maternal trade-offs," Journal of Zoology, vol. 245, no. 4, pp. 457-465, 1998. 
[14] M. Hebblewhite, E. Merrill, and G. McDermid, "A multi-scale test of the forage maturation hypothesis in a partially migratory ungulate population," Ecological Monographs, vol. 78, no. 2, pp. 141-166, 2008.

[15] J. M. Smith and G. R. Price, "The logic of animal conflict," Nature, vol. 246, no. 5427, pp. 15-18, 1973.

[16] M. Festa-Bianchet, "Seasonal range selection in bighorn sheep: conflicts between forage quality, forage quantity, and predator avoidance," Oecologia, vol. 75, no. 4, pp. 580-586, 1988.

[17] V. Geist, Mountain Sheep. A Study in Behavior and Evolution, University of Chicago Press, Chicago, Ill, USA, 1971.

[18] J. D. Wehausen, Sierra Nevada bighorn sheep: history and population ecology [Ph.D. thesis], University of Michigan, Ann Arbor, Mich, USA, 1980.

[19] J. L. Rachlow and R. T. Bowyer, "Variability in maternal behavior by Dall's sheep: environmental tracking or adaptive strategy?" Journal of Mammalogy, vol. 75, no. 2, pp. 328-337, 1994.

[20] J. C. Whiting, R. T. Bowyer, J. T. Flinders, V. C. Bleich, and J. G. Kie, "Sexual segregation and use of water by bighorn sheep: implications for conservation," Animal Conservation, vol. 13, no. 6, pp. 541-548, 2010.

[21] V. C. Bleich, "Mountain sheep and coyotes: patterns of predator evasion in a mountain ungulate," Journal of Mammalogy, vol. 80, no. 1, pp. 283-289, 1999.

[22] H. Kruuk, The Spotted Hyena: A Study of Predation and Social Behavior, University of Chicago Press, Chicago, Ill, USA, 1972.

[23] J. Berger, "Group size, foraging, and antipredator ploys: an analysis of bighorn sheep decisions," Behavioral Ecology and Sociobiology, vol. 4, no. 1, pp. 91-100, 1978.

[24] K. L. Risenhoover and J. A. Bailey, "Visibility: an important factor for an indigenous, low-elevation bighorn herd in Colorado," in Bennial Symposium of the Northern Wild Sheep and Goat Council, vol. 2, pp. 18-28, 1980.

[25] J. Berger, J. E. Swenson, and I.-L. Persson, "Recolonizing carnivores and naïve prey: conservation lessons from pleistocene extinctions," Science, vol. 291, no. 5506, pp. 1036-1039, 2001.

[26] J. S. Brown, J. W. Laundré, and M. Gurung, "The ecology of fear: optimal foraging, game theory, and trophic interactions," Journal of Mammalogy, vol. 80, no. 2, pp. 385-399, 1999.

[27] B. P. Kotler and R. D. Holt, "Predation and competition: the interaction of two types of species interactions," Oikos, vol. 54, no. 2, pp. 256-260, 1989.

[28] J. Berger and J. D. Wehausen, "Consequences of a mammalian predator-prey disequilibrium in the Great Basin Desert," Conservation Biology, vol. 5, no. 2, pp. 244-248, 1991.

[29] C. A. Schroeder, R. T. Bowyer, V. C. Bleich, and T. R. Stephenson, "Sexual segregation in Sierra Nevada bighorn sheep, Ovis canadensis sierrae: ramifications for conservation," Arctic, Antarctic, and Alpine Research, vol. 42, no. 4, pp. 476-489, 2010.

[30] A. Frid, "Vigilance by female Dall's sheep: interactions between predation risk factors," Animal Behaviour, vol. 53, no. 4, pp. 799808, 1997.

[31] L. J. McCann, "Ecology of the mountain sheep," American Midland Naturalist, vol. 56, no. 2, pp. 297-324, 1956.

[32] V. C. Bleich, R. T. Bowyer, and J. D. Wehausen, "Sexual segregation in mountain sheep: resources or predation?" Wildlife Monographs, vol. 134, pp. 1-50, 1997.

[33] C. J. Farmer, D. K. Person, and R. T. Bowyer, "Risk factors and mortality of black-tailed deer in a managed forest landscape,"
Journal of Wildlife Management, vol. 70, no. 5, pp. 1403-1415, 2006.

[34] R. T. Bowyer, "Sexual segregation in ruminants: definitions, hypotheses, and implications for conservation and management," Journal of Mammalogy, vol. 85, no. 6, pp. 1039-1052, 2004.

[35] S. A. Oehlers, R. T. Bowyer, F. Huettmann, D. K. Person, and W. B. Kessler, "Sex and scale: implications for habitat selection by Alaskan moose Alces alces gigas," Wildlife Biology, vol. 17, no. 1, pp. 67-84, 2011.

[36] S. Creel and D. Christianson, "Relationships between direct predation and risk effects," Trends in Ecology and Evolution, vol. 23, no. 4, pp. 194-201, 2008.

[37] S. L. Lima, "Nonlethal effects in the ecology of predator-prey interactions," BioScience, vol. 48, no. 1, pp. 25-34, 1998.

[38] S. Creel, D. Christianson, S. Liley, and J. A. Winnie Jr., "Predation risk affects reproductive physiology and demography of elk," Science, vol. 315, no. 5814, p. 960, 2007.

[39] A. D. Middleton, M. J. Kauffman, D. E. McWhirter et al., "Animal migration amid shifting patterns of phenology and predation: lessons from a Yellowstone elk herd," Ecology, vol. 94, no. 6, pp. 1245-1256, 2013.

[40] W. J. Ripple, E. J. Larsen, R. A. Renkin, and D. W. Smith, "Trophic cascades among wolves, elk and aspen on Yellowstone National Park's northern range," Biological Conservation, vol. 102, no. 3, pp. 227-234, 2001.

[41] J. D. Wehausen, "Effects of mountain lion predation on bighorn sheep in the Sierra Nevada and Granite Mountains of California," Wildlife Society Bulletin, vol. 24, no. 3, pp. 471-479, 1996.

[42] U.S. Fish and Wildlife Service, Recovery Plan for the Sierra Nevada Bighorn Sheep (Ovis canadensis californiana), U.S. Fish and Wildlife Service, Portland, Ore, USA, 2008.

[43] M. Festa-Bianchet, T. Coulson, J.-M. Gaillard, J. T. Hogg, and F. Pelletier, "Stochastic predation events and population persistence in bighorn sheep," Proceedings of the Royal Society B: Biological Sciences, vol. 273, no. 1593, pp. 1537-1543, 2006.

[44] E. M. Rominger, H. A. Whitlaw, D. L. Weybright, W. C. Dunn, and W. B. Ballard, "The influence of mountain lion predation on bighorn sheep translocations," Journal of Wildlife Management, vol. 68, no. 4, pp. 993-999, 2004.

[45] P. I. Ross, M. G. Jalkotzy, and M. Festa-Blanchet, "Cougar predation on bighorn sheep in southwestern Alberta during winter," Canadian Journal of Zoology, vol. 75, no. 5, pp. 771-775, 1997.

[46] R. J. Schaefer, S. G. Torres, and V. C. Bleich, "Survivorship and cause-specific mortality in sympatric populations of mountain sheep and mule deer," California Fish and Game, vol. 86, no. 2, pp. 127-135, 2000.

[47] B. M. Pierce, V. C. Bleich, K. L. Monteith, and R. T. Bowyer, "Top-down versus bottom-up forcing: evidence from mountain lions and mule deer," Journal of Mammalogy, vol. 93, no. 4, pp. 977-988, 2012.

[48] M. D. Roos, The Hydrology of the 1987-1992 California Drought, State of California, Resources Agency, Department of Water Resources, Division of Flood Management, Sacramento, Calif, USA, 1992.

[49] D. R. Stevens and N. J. Goodson, "Assessing effects of removals for transplanting on a high-elevation bighorn sheep population," Conservation Biology, vol. 7, no. 4, pp. 908-915, 1993.

[50] J. T. Villepique, B. M. Pierce, V. C. Bleich, and R. T. Bowyer, "Diet of cougars (Puma concolor) following a decline in a population of mule deer (Odocoileus hemionus): lack of evidence for 
switching prey," The Southwestern Naturalist, vol. 56, no. 2, pp. 187-192, 2011.

[51] J. Dozier, "Spectral signature of alpine snow cover from the Landsat Thematic Mapper," Remote Sensing of Environment, vol. 28, pp. 9-22, 1989.

[52] D. K. Hall, G. A. Riggs, and V. V. Salomonson, "Development of methods for mapping global snow cover using moderate resolution imaging spectroradiometer data," Remote Sensing of Environment, vol. 54, no. 2, pp. 127-140, 1995.

[53] N. Pettorelli, J. O. Vik, A. Mysterud, J.-M. Gaillard, C. J. Tucker, and N. C. Stenseth, "Using the satellite-derived NDVI to assess ecological responses to environmental change," Trends in Ecology \& Evolution, vol. 20, no. 9, pp. 503-510, 2005.

[54] S. Hamel, M. Garel, M. Festa-Bianchet, J.-M. Gaillard, and S. D. Côté, "Spring normalized difference vegetation index (NDVI) predicts annual variation in timing of peak faecal crude protein in mountain ungulates," Journal of Applied Ecology, vol. 46, no. 3, pp. 582-589, 2009.

[55] D. M. Leslie Jr., R. T. Bowyer, and J. A. Jenks, "Facts from feces: nitrogen still measures up as a nutritional index for mammalian herbivores," Journal of Wildlife Management, vol. 72, no. 6, pp. 1420-1433, 2008.

[56] H. E. Johnson, M. Hebblewhite, T. R. Stephenson, D. W. German, B. M. Pierce, and V. C. Bleich, "Evaluating apparent competition in limiting the recovery of an endangered ungulate," Oecologia, vol. 171, no. 1, pp. 295-307, 2013.

[57] T. I. Storer and R. L. Usinger, Sierra Nevada Natural History, University of California Press, Berkeley, Calif, USA, 1968.

[58] P. R. Krausman, J. J. Hervert, and L. L. Ordway, "Capturing deer and mountain sheep with a net-gun," Wildlife Society Bulletin, vol. 13, no. 1, pp. 71-73, 1985.

[59] B. M. Pierce, V. C. Bleich, C.-L. B. Chetkiewicz, and J. D. Wehausen, "Timing of feeding bouts of mountain lions," Journal of Mammalogy, vol. 79, no. 1, pp. 222-226, 1998.

[60] B. M. Pierce, V. C. Bleich, and R. T. Bowyer, "Selection of mule deer by mountain lions and coyotes: effects of hunting style, body size, and reproductive status," Journal of Mammalogy, vol. 81, no. 2, pp. 462-472, 2000.

[61] H. J. Kilpatrick, A. J. DeNicola, and M. R. Ellingwood, "Comparison of standard and transmitter-equipped darts for capturing white-tailed deer," Wildlife Society Bulletin, vol. 24, no. 2, pp. 306-310, 1996.

[62] R. S. Sikes, W. L. Gannon, and The Animal Care and Use Committee of the American Society of Mammalogists, "Guidelines of the American Society of Mammalogists for the use of wild mammals in research," Journal of Mammalogy, vol. 92, no. 1, pp. 235-253, 2011.

[63] A. C. D. Quinn, D. M. Williams, and W. F. Porter, "Postcapture movement rates can inform data-censoring protocols for GPScollared animals," Journal of Mammalogy, vol. 93, no. 2, pp. 456463, 2012.

[64] J. T. Villepique, V. C. Bleich, B. M. Pierce, T. R. Stephenson, R. Botta, and R. T. Bowyer, "Evaluating GPS collar error: a critical evaluation of Televilt Posrec-Science collars and a method for screening location data," California Fish and Game, vol. 94, no. 4, pp. 155-168, 2008.

[65] K. B. Rogers and G. C. White, "Analysis of movement and habitat use from telemetry data," in Analysis and Interpretation of Freshwater Fisheries Data, pp. 625-676, 2007.

[66] J. G. Kie, "A rule-based ad hoc method for selecting a bandwidth in kernel home-range analyses," Animal Biotelemetry, vol. 1, article 13, 2013.
[67] R. G. D'Eon and D. Delparte, "Effects of radio-collar position and orientation on GPS radio-collar performance, and the implications of PDOP in data screening," Journal of Applied Ecology, vol. 42, no. 2, pp. 383-388, 2005.

[68] J. L. Frair, J. Fieberg, M. Hebblewhite, F. Cagnacci, N. J. DeCesare, and L. Pedrotti, "Resolving issues of imprecise and habitat-biased locations in ecological analyses using GPS telemetry data," Philosophical Transactions of the Royal Society B: Biological Sciences, vol. 365, no. 1550, pp. 2187-2200, 2010.

[69] J. W. Cain III, P. R. Krausman, B. D. Jansen, and J. R. Morgart, "Influence of topography and GPS fix interval on GPS collar performance," Wildlife Society Bulletin, vol. 33, no. 3, pp. 926934, 2005.

[70] J. L. Frair, S. E. Nielsen, E. H. Merrill et al., "Removing GPS collar bias in habitat selection studies," Journal of Applied Ecology, vol. 41, no. 2, pp. 201-212, 2004.

[71] K. T. Weber, M. Burcham, and C. Les Marcum, "Assessing independence of animal locations with association matrices," Journal of Range Management, vol. 54, no. 1, pp. 21-24, 2001.

[72] D. H. Johnson, "The comparison of usage and availability measurements for evaluating resource preference," Ecology, vol. 61, no. 1, pp. 65-71, 1980.

[73] R. A. Montgomery, G. J. Roloff, and J. M. V. Hoef, "Implications of ignoring telemetry error on inference in wildlife resource use models," Journal of Wildlife Management, vol. 75, no. 3, pp. 702708, 2011.

[74] H. Beyer, "Hawth's analysis tools for ArcGIS," 2005, http://spatialecology.com/htools/.

[75] S. M. Arthur, B. F. J. Manly, L. L. McDonald, and G. W. Garner, "Assessing habitat selection when availability changes," Ecology, vol. 77, no. 1, pp. 215-227, 1996.

[76] M. S. Boyce, "Scale for resource selection functions," Diversity and Distributions, vol. 12, no. 3, pp. 269-276, 2006.

[77] C. J. Johnson, S. E. Nielsen, E. H. Merrill, T. L. McDonald, and M. S. Boyce, "Resource selection functions based on useavailability data: theoretical motivation and evaluation methods," Journal of Wildlife Management, vol. 70, no. 2, pp. 347-357, 2006.

[78] K. H. Knopff, Cougar predation in a multi-prey system in WestCentral Alberta [Ph.D. thesis], University of Alberta, Edmundton, Canada, 2010.

[79] K. H. Knopff, A. A. Knopff, M. B. Warren, and M. S. Boyce, "Evaluating global positioning system telemetry techniques for estimating cougar predation parameters," Journal of Wildlife Management, vol. 73, no. 4, pp. 586-597, 2009.

[80] A. R. Rodgers, A. P. Carr, H. L. Beyer, L. Smith, and J. G. Kie, HRT: Home Range Tools for ArcGIS. Version 1.1, Ontario Ministry of Natural Resources, Centre for Northern Forest Ecosystem Research, Thunder Bay, Canada, 2007.

[81] K. B. Pierce Jr., T. Lookingbill, and D. Urban, "A simple method for estimating potential relative radiation (PRR) for landscapescale vegetation analysis," Landscape Ecology, vol. 20, no. 2, pp. 137-147, 2005.

[82] R. T. Bowyer and J. G. Kie, "Effects of scale on interpreting lifehistory characteristics of ungulates and carnivores," Diversity and Distributions, vol. 12, no. 3, pp. 244-257, 2006.

[83] J. G. Kie, R. T. Bowyer, M. C. Nicholson, B. B. Boroski, and E. R. Loft, "Landscape heterogeneity at differing scales: effects on spatial distribution of mule deer," Ecology, vol. 83, no. 2, pp. 530544, 2002. 
[84] J. A. K. Maier, J. M. Ver Hoef, A. D. McGuire, R. T. Bowyer, L. Saperstein, and H. A. Maier, "Distribution and density of moose in relation to landscape characteristics: effects of scale," Canadian Journal of Forest Research, vol. 35, no. 9, pp. 22332243, 2005.

[85] S. E. Sesnie, B. G. Dickson, S. S. Rosenstock, and J. M. Rundall, "A comparison of landsat TM and MODIS vegetation indices for estimating forage phenology in desert bighorn sheep (Ovis canadensis nelsoni) habitat in the Sonoran desert, USA," International Journal of Remote Sensing, vol. 33, no. 1, pp. 276286, 2012.

[86] L. Andaloro and R. R. Ramey, The Relocation of Bighorn Sheep in the Sierra Nevada of California, vol. 7 of Environmental Field Program Publication, University of California, Santa Cruz, Calif, USA, 1981.

[87] G. Chander and D. P. Groeneveld, "Intra-annual NDVI validation of the Landsat 5 TM radiometric calibration," International Journal of Remote Sensing, vol. 30, no. 6, pp. 1621-1628, 2009.

[88] SAS Institute Inc, SAS/STAT 9.3 User's Guide, SAS Institute Inc, Cary, NC, USA, 2011.

[89] R. A. Long, J. G. Kie, R. T. Bowyer, and M. A. Hurley, "Resource selection and movements by female mule deer Odocoileus hemionus: effects of reproductive stage," Wildlife Biology, vol. 15, no. 3, pp. 288-298, 2009.

[90] B. F. J. Manly, L. L. McDonald, D. L. Thomas, T. L. McDonald, and W. P. Erickson, Resource Selection by Animals: Statistical Design and Analysis for Field Studies, Kluwer Academic, Dordrecht, The Netherlands, 2002.

[91] P. D. McLoughlin, D. W. Morris, D. Fortin, E. Vander Wal, and A. L. Contasti, "Considering ecological dynamics in resource selection functions," Journal of Animal Ecology, vol. 79, no. 1, pp. 4-12, 2010.

[92] P. D. Allison, Logistic Regression Using the SAS System: Theory and Application, SAS Institute, Cary, NC, USA, 1999.

[93] D. W. Hosmer and S. Lemeshow, Applied Logistic Regression, John Wiley \& Sons, New York, NY, USA, 2000.

[94] K. P. Burnham and D. R. Anderson, Model Selection and MultiModel Inference: A Practical Information-Theoretic Approach, Springer, New York, NY, USA, 2002.

[95] K. P. Burnham and D. R. Anderson, "Multimodel inference understanding AIC and BIC in model selection," Sociological Methods and Research, vol. 33, no. 2, pp. 261-304, 2004.

[96] D. P. Anderson, M. G. Turner, J. D. Forester et al., "Scaledependent summer resource selection by reintroduced elk in Wisconsin, USA," Journal of Wildlife Management, vol. 69, no. 1, pp. 298-310, 2005.

[97] M. S. Boyce, P. R. Vernier, S. E. Nielsen, and F. K. A. Schmiegelow, "Evaluating resource selection functions," Ecological Modelling, vol. 157, no. 2-3, pp. 281-300, 2002.

[98] M. S. Boyce, J. S. Mao, E. H. Merrill et al., "Scale and heterogeneity in habitat selection by elk in Yellowstone National Park," Ecoscience, vol. 10, no. 4, pp. 421-431, 2003.

[99] R. A. Long, J. D. Muir, J. L. Rachlow, and J. G. Kie, "A comparison of two modeling approaches for evaluating wildlife habitat relationships," Journal of Wildlife Management, vol. 73, no. 2, pp. 294-302, 2009.

[100] W. J. Conover, Practical Nonparametric Statistics, John Wiley \& Sons, New York, NY, USA, 1999.

[101] B. M. Pierce, V. C. Bleich, and R. T. Bowyer, "Social organization of mountain lions: does a land-tenure system regulate population size?" Ecology, vol. 81, no. 6, pp. 1533-1543, 2000.
[102] L. Greene, Short-term effects of wildfire on Sierra Nevada bighorn sheep habitat ecology [M.S. thesis], The University of Montana, Missoula, Mont, USA, 2010.

[103] S. G. Torres, T. M. Mansfield, J. E. Foley, T. Lupo, and A. Brinkhaus, "Mountain lion and human activity in California: testing speculations," Wildlife Society Bulletin, vol. 24, no. 3, pp. 451-460, 1996.

[104] M. S. Mooring, T. A. Fitzpatrick, T. T. Nishihira, and D. D. Reisig, "Vigilance, predation risk, and the Allee effect in desert bighorn sheep," Journal of Wildlife Management, vol. 68, no. 3, pp. 519-532, 2004.

[105] J. D. Wehausen, "The role of precipitation and temperature in the winter range diet quality of mountain sheep of the Mount Baxter herd, Sierra Nevada," in Proceedings of the Biennial Symposium of the North American Wild Sheep and Goat Council, vol. 8, pp. 279-292, Cody, Wyo, USA, 1992.

[106] V. C. Bleich, J. D. Wehausen, K. R. Jones, and R. A. Weaver, "Status of bighorn sheep in California, 1989 and translocations from 1971 through 1989," Desert Bighorn Council Transactions, vol. 34, pp. 24-26, 1990.

[107] V. C. Bleich, R. T. Bowyer, A. M. Pauli, R. L. Vernoy, and R. W. Anthes, "Responses of mountain sheep to helicopter surveys," California Fish \& Game, vol. 76, no. 4, pp. 197-204, 1990.

[108] A. Frid, "Dall's sheep responses to overflights by helicopter and fixed-wing aircraft," Biological Conservation, vol. 110, no. 3, pp. 387-399, 2003.

[109] C. A. Stockwell, G. C. Bateman, and J. Berger, "Conflicts in national parks: a case study of helicopters and bighorn sheep time budgets at the grand canyon," Biological Conservation, vol. 56, no. 3, pp. 317-328, 1991.

[110] V. C. Bleich, R. T. Bowyer, A. M. Pauli, M. C. Nicholson, and R. W. Anthes, "Mountain sheep Ovis canadensis and helicopter surveys: ramifications for the conservation of large mammals," Biological Conservation, vol. 70, no. 1, pp. 1-7, 1994.

[111] I. M. Cowan, "Distribution and variation in the native sheep of North America," The American Midland Naturalist, vol. 24, no. 3, pp. 505-580, 1940.

[112] M. Culver, W. E. Johnson, J. Pecon-Slattery, and S. J. O’Brien, "Genomic ancestry of the American puma (Puma concolor)," Journal of Heredity, vol. 91, no. 3, pp. 186-197, 2000.

[113] E. R. Cook, C. A. Woodhouse, C. M. Eakin, D. H. Meko, and D. W. Stahle, "Long-term aridity changes in the western United States," Science, vol. 306, no. 5698, pp. 1015-1018, 2004.

[114] T. E. Kucera, Ecology and population dynamics of mule deer in the eastern Sierra Nevada, California [Ph.D. thesis], University California, Berkeley, Calif, USA, 1988.

[115] T. E. Kucera, "Fecal indicators, diet and population parameters in mule deer," Journal of Wildlife Management, vol. 61, no. 2, pp. 550-560, 1997.

[116] P. A. Abrams, "Implications of dynamically variable traits for identifying, classifying, and measuring direct and indirect effects in ecological communities," The American Naturalist, vol. 146, no. 1, pp. 112-134, 1995.

[117] M. J. Kauffman, J. F. Brodie, and E. S. Jules, "Are wolves saving Yellowstone's aspen? A landscape-level test of a behaviorally mediated trophic cascade," Ecology, vol. 91, no. 9, pp. 2742-2755, 2010. 

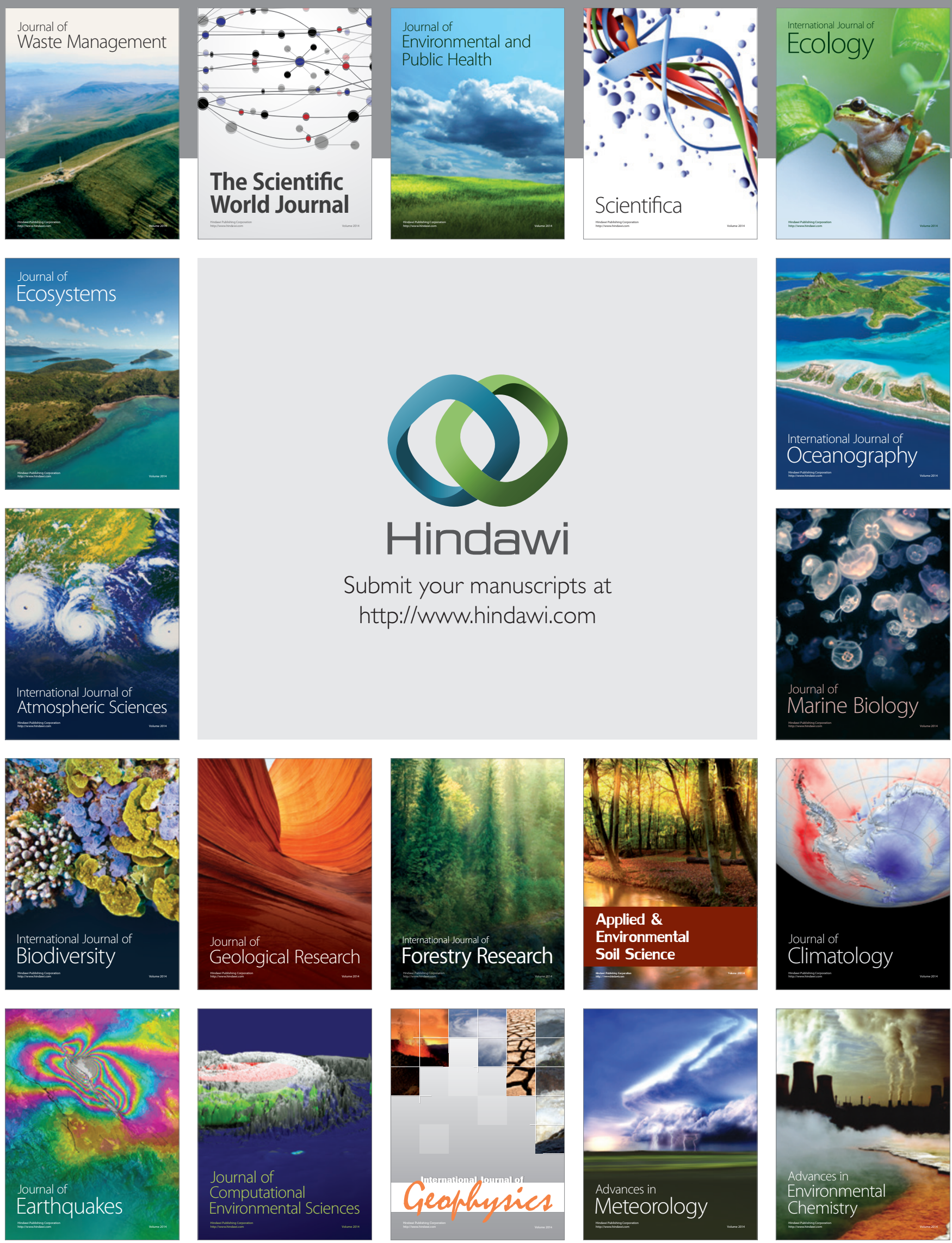